\title{
THE REPRESENTATION OF THE BODY SURFACE IN S-I OF CATS $^{1}$
}

\author{
DANIEL J. FELLEMAN, ${ }^{2}$ JOHN T. WALL, CATHERINE G. CUSICK, AND JON H. KAAS ${ }^{3}$ \\ Department of Psychology, Vanderbilt University, Nashville, Tennessee 37240 \\ Received August 30, 1982; Revised March 17, 1983; Accepted March 17, 1983
}

\begin{abstract}
In both cats and monkeys, the traditional region of the first somatosensory area of cortex, S-I, has been described as containing four strip-like architectonic fields, areas $3 a, 3 b, 1$, and 2 . In monkeys, a number of recent studies have provided evidence that each of these architectonic fields constitutes a separate representation of the body. Because of the observations in monkeys, we decided to re-examine the S-I region of cats to determine whether the evidence supported the traditional concept of a single representation, or the existence of several representations related to the described architectonic fields. Microelectrode multiunit mapping techniques were used to determine the somatotopic organization of the S-I region of 10 cats. The results indicate that a single representation of the body surface occupies most or all of the traditional S-I region including cortex defined as area " $3 \mathrm{~b}$, , area " 1 ," and much of area " 2 ," but excluding area " $3 a$." Neurons throughout this single representation were activated by cutaneous stimuli, indicating that all parts of S-I receive input from cutaneous receptors. Neurons in area 3a were activated by inputs from deep receptors, as reported by others. Neurons caudal to S-I were activated by cutaneous stimuli and appeared to constitute the additional body surface representations of S-II and possibly S-III. Thus, the significance of the architectonic fields " $3 \mathrm{~b}$, " " 1 ," and " 2 " is quite different in cats than in monkeys. We propose that most or all of these three fields, as described in cats, constitute the homologue of area $3 \mathrm{~b}$ in monkeys.
\end{abstract}

From the first mapping studies of somatosensory cortex, the primary area, S-I, of cats has been defined as a single systematic representation of the body surface (Adrian, 1941, 1943; Haynes and Woolsey, 1944; Woolsey and Fairman, 1946). When it was noted that stimulating a single body location could produce more than one focus of activity in cortex (Adrian, 1940; Marshall et al., 1941), the additional sites of activation were assigned to other somatosensory representations, S-II (Adrian, 1943; Woolsey and Fairman, 1946) and S-III (Tasker, 1960; Darian-Smith et al., 1966). The concept of S-I as single cutaneous representation became firmly established with the acceptance of the familiar summary of the organization as a distorted figurine or "homunculus" (Woolsey, 1958).

The cortex known as S-I was also thought to contain

\footnotetext{
${ }^{1}$ We thank M. M. Merzenich, R. J. Nelson, T. P. Pons, M. Sur, and R. E. Weller for helpful comments. This research was supported by National Institute of Mental Health Fellowship 1F3 MH08179 to D. J. F. and National Institutes of Health Grant NS16446 to J. H. K.

${ }^{2}$ Present address: Division of Biology, California Institute of Technology, 216-76 Pasadena, CA 91125.

${ }^{3}$ To whom correspondence should be addressed.
}

a single representation in other mammals. Thus, the discovery of separate representations in the "S-I" cortex of monkeys was somewhat surprising. Cortex originally included in "S-I" of monkeys appears to contain four parallel, mediolateral, strip-like representations of the body (Merzenich et al., 1978; Kaas et al., 1979; Nelson et al., 1980; Sur et al., 1982; Felleman et al., 1983; for a recent alternative point of view, see McKenna et al., 1982). The most rostral of these representations is activated by predominantly deep receptors, probably muscle afferents; the middle two representations are activated by cutaneous receptors; and the most caudal representation relates to deep and cutaneous receptors. Each of these representations appears to correspond with one of the four generally recognized architectonic fields of postcentral parietal cortex of monkeys, areas $3 a, 3 b, 1$, and 2.

The reinterpretation of the organization of parietal cortex in monkeys raises the possibility that the S-I region has been incorrectly considered as a single representation in other mammals. Detailed microelectrode mapping studies in a number of smooth-brained mammals-including rats (Welker, 1971), squirrels (Sur et al., 1978), and tree shrews (Sur et al., 1980b) - has con- 
vinced us that this is not typically the case; the region traditionally identified as S-I contains a single representation. This single cutaneous representation appears to be the homologue of area $3 \mathrm{~b}$ in monkeys (Merzenich et al., 1978; Kaas, 1983). The one mammal where re-examination seemed appropriate, however, was the domestic cat. As for monkeys, the S-I region of cats has been divided into four mediolateral strip-like architectonic fields, areas 3a, 3b, 1, and 2 (Hassler and Muhs-Clement, 1964). Also in apparent similarity to monkeys, the S-I region of cats has classically been described as having a nonuniform distribution of inputs from deep and cutaneous receptors (Mountcastle, 1957). In monkeys, the nonuniform distribution is now explained in terms of the separate representations.

Although the organization of the S-I region of cats has been described a number of times (e.g., Marshall et al., 1941; Adrian, 1941, 1943; Haynes and Woolsey, 1944; Woolsey, 1958; Rubel, 1971; Dykes et al., 1980b; McKenna et al., 1981), the relative cortical locations of body parts have not been specified in enough detail to be certain that separate parallel representations do not exist. Thus, recent investigators have raised the question of separate representations in "S-I" of cats (Dykes et al., 1980b). A brief report of some of the observations appeared previously (Felleman et al., 1981).

\section{Materials and Methods}

Electrophysiological mapping experiments were conducted on somatosensory cortex of 10 adult cats of both sexes. The methods employed in this study are similar to those previously described from this laboratory (Merzenich et al., 1978; Nelson et al., 1980). Initial surgical anesthesia was achieved by either ketamine $\mathrm{HCl}(35 \mathrm{mg} /$ $\mathrm{kg}$, i.m.) or sodium pentobarbital $(40 \mathrm{mg} / \mathrm{kg}$, i.p.) and was supplemented, as needed, during the course of the experiment. Body temperature was maintained at $37^{\circ} \mathrm{C}$. The anterior cortex was exposed unilaterally by a large craniotomy typically extending from well behind the ansate sulcus caudally to beyond the cruciate sulcus rostrally, and from the midline of the hemisphere to the anterior coronal gyrus. A well of dental acrylic was formed around the craniotomy and filled with silicone fluid. The dura was carefully removed, and a high resolution photograph of the cortex was taken at the intended angle of electrode penetration. The cortical blood vessel pattern was viewed with a surgical microscope, and the brain photograph was used to carefully site and record the locations of up to several hundred electrode penetrations into exposed cortex and down the banks of the various sulci.

Parylene-C-coated tungsten microelectrodes with impedances of 0.7 to 1.5 megohms (at $1 \mathrm{kHz}$ ) were used to provide multiunit recordings at selected sites throughout the S-I cortex. Neural activity was conventionally amplified and monitored with an oscilloscope and audiomonitor. Individual recording sites were spaced in a grid-like pattern with an interpenetration distance of typically 200 to $300 \mu \mathrm{m}$. Depth penetrations were made down the banks of the coronal and ansate sulci as well as down the medial wall of the hemisphere in order to explore completely the extent of the S-I cortex. In these depth penetrations, recording sites were typically separated by $250 \mu \mathrm{m}$. For each recording site, a receptive field was carefully determined using light tactile stimulation with a fine-tipped glass probe or a fine camel's-hair brush. The response modality was evaluated as cutaneous when light skin indentation and hair movement were effective stimuli. Recording sites requiring more intense stimuli were simply classified as "high threshold," and those easily activated by joint or muscle movement without any apparent cutaneous receptive field were classified as "deep." Cutaneous receptive field locations and dimensions were drawn on scaled outlines of the appropriate body surfaces.

In any given experiment, receptive fields were typically determined at 300 to 500 recording sites. The body surface map was then reconstructed on a surface view or on a planar view of the convoluted cortical surface (Nelson et al., 1980). Figure 1 illustrates the way cortical maps are produced. The experiment shown explored the region of the representation of the hindlimb, trunk, forelimb, and part of the face in S-I. Each dot on the left marks the location of an individual electrode penetration. The body surface map generated from these data points is shown on the right. Lines are drawn around individual points with similar receptive field locations. Thus, neurons in the region marked trunk had receptive fields centered on the trunk. As described elsewhere, these lines describe topographic features and do not necessarily indicate discontinuities in the cortical map (Nelson et al., 1980). The outer boundary of S-I was determined by sudden changes in responsiveness or response submodality, and by changes in somatotopic organization in dicating S-II or S-III. Electrolytic lesions were placed at selected sites in order to provide markers for physiological borders which could then be related to cortical cytoarchitecture.

At the conclusion of each experiment the cat was deeply anesthetized with sodium pentobarbital and perfused intracardially with normal saline followed by $10 \%$ formol saline. The brain was carefully removed, photographed, frozen, and cut at 25 or $50 \mu \mathrm{m}$ in the sagittal or frontal plane. Sections were stained with cresyl violet.

\section{Results}

The overall organization of S-I in the cat is shown in Figures 1 and 2. Figure 1 illustrates the results from an attempt to determine much of the somatotopic pattern of S-I in a single animal. The outlined cortex on the surface view of the brain on the left indicates the estimated extent of S-I in this experiment, and dots mark electrode penetrations within or near S-I.

Because it was difficult to explore fully the S-I region in a single experiment, a more typical procedure was to record extensively from a portion of S-I in an effort to determine the organization of that part in detail. Thus, a more complete overview of the organization of S-I is provided in Figure 2, which was constructed by combining partial maps from three individual cats, using regions of topological overlap to join the three parts. The banks of the coronal sulcus have been unfolded to show hidden parts of the map. This report further describes and 


\section{CAT S-I 80-130}
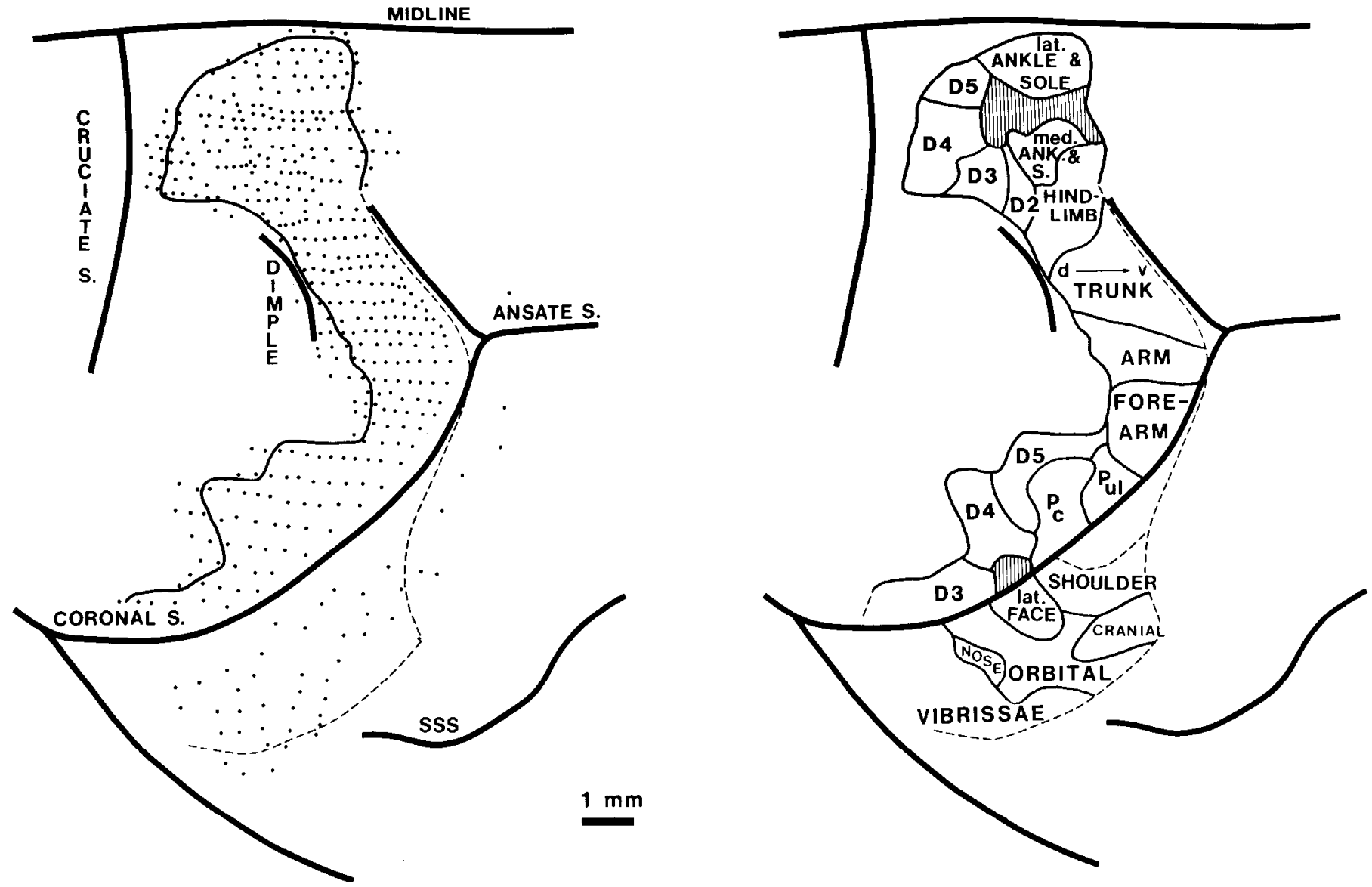

Figure 1. The organization of S-I in a cat. Left, Dots mark electrode penetrations on a dorsolateral view of parietal cortex of cat 80-130. Recordings were obtained for surface cortex and for cortex in ansate and coronal sulci. S-I is outlined. Right, A cortical map of the somatotopic organization of S-I as determined from receptive field locations for recording sites in the electrode penetrations on the left. Recording sites with receptive fields on given body parts have been outlined. $P c$, central pad and adjacent ventral surface of forepaw and hindpaw; $P u l$, ulnar pad at wrist; $D_{1}$ to $D_{5}$, digits of limbs. The dorsal hindpaw and forepaw are shaded.

documents the organization of $\mathrm{S}-\mathrm{I}$ in cats and relates the representation to cortical architecture.

\section{The responsiveness, boundaries, and location of $S-I$}

$\mathrm{S}-\mathrm{I}$ was defined in the present experiments as a single systematic representation of the contralateral body surface. Recording sites throughout S-I responded to cutaneous stimuli, and the receptive fields for these recording sites formed a somatotopic pattern that was orderly, largely continuous, and did not repeat body parts. Of course, different regions of a single body part were sometimes represented in two different locations due to discontinuities in the map, but this does not imply the double representation of any body part. The homogeneity of the representation in terms of responsiveness should be stressed. While occasional unresponsive recording sites or recording sites activated by high threshold stimuli did occur, they did not appear to have any systematic relation to body part or to rostrocaudal or mediolateral location in S-I. We regard these few sites as indicating local depressions in neural activity, possibly as the result of damage, or possibly indicating narrow discontinuities in the representations as observed in rodents (Welker, 1971; Sur et al., 1978). There was no evidence for recording sites within S-I that were activated solely by noncutaneous stimuli. Although the possibility of noncutaneous inputs exists (see "Discussion"), none were clearly detected.

The rostral border of S-I, as defined here, was marked by a dramatic change in responsiveness so that recording sites just across the border changed suddenly from being activated by low threshold cutaneous stimuli to being unresponsive to low threshold cutaneous stimuli and responsive to high threshold stimuli, such as taps, and body movements. These observations are consistent with the finding that the neurons in area $3 \mathrm{a}$ are activated by muscle receptors (e.g., Dykes et al., 1980b). We did not include this rostral noncutaneous zone of cortex in S-I because $(a)$ it was activated by body parts already represented in a systematic pattern in S-I, $(b)$ the locations of the receptive fields for neurons in the zone did not conform to or extend the somatotopic pattern in S-I, (c) the neurons were activated by a different submodality, and $(d)$ when recording results were compared to cortical architecture (see below), the neurons activated by non- 


\section{CAT S-I}

\section{A. Surface View}

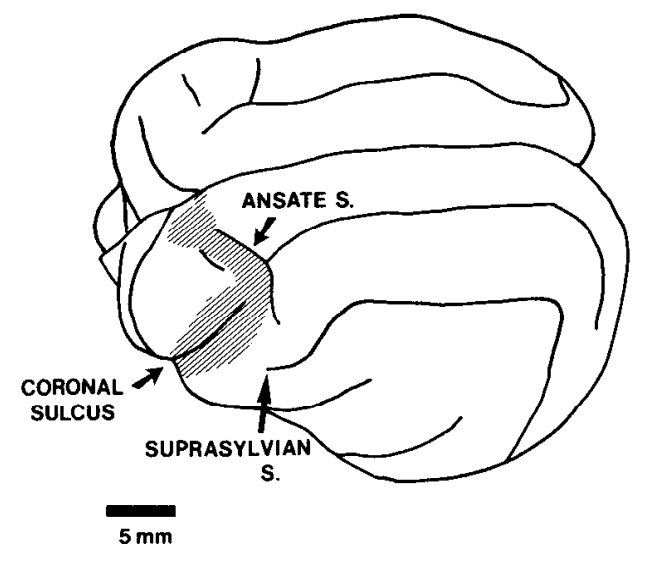

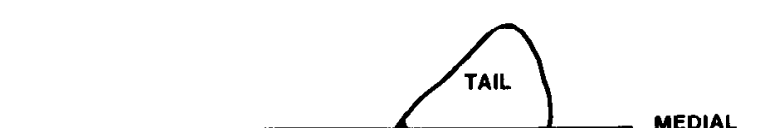
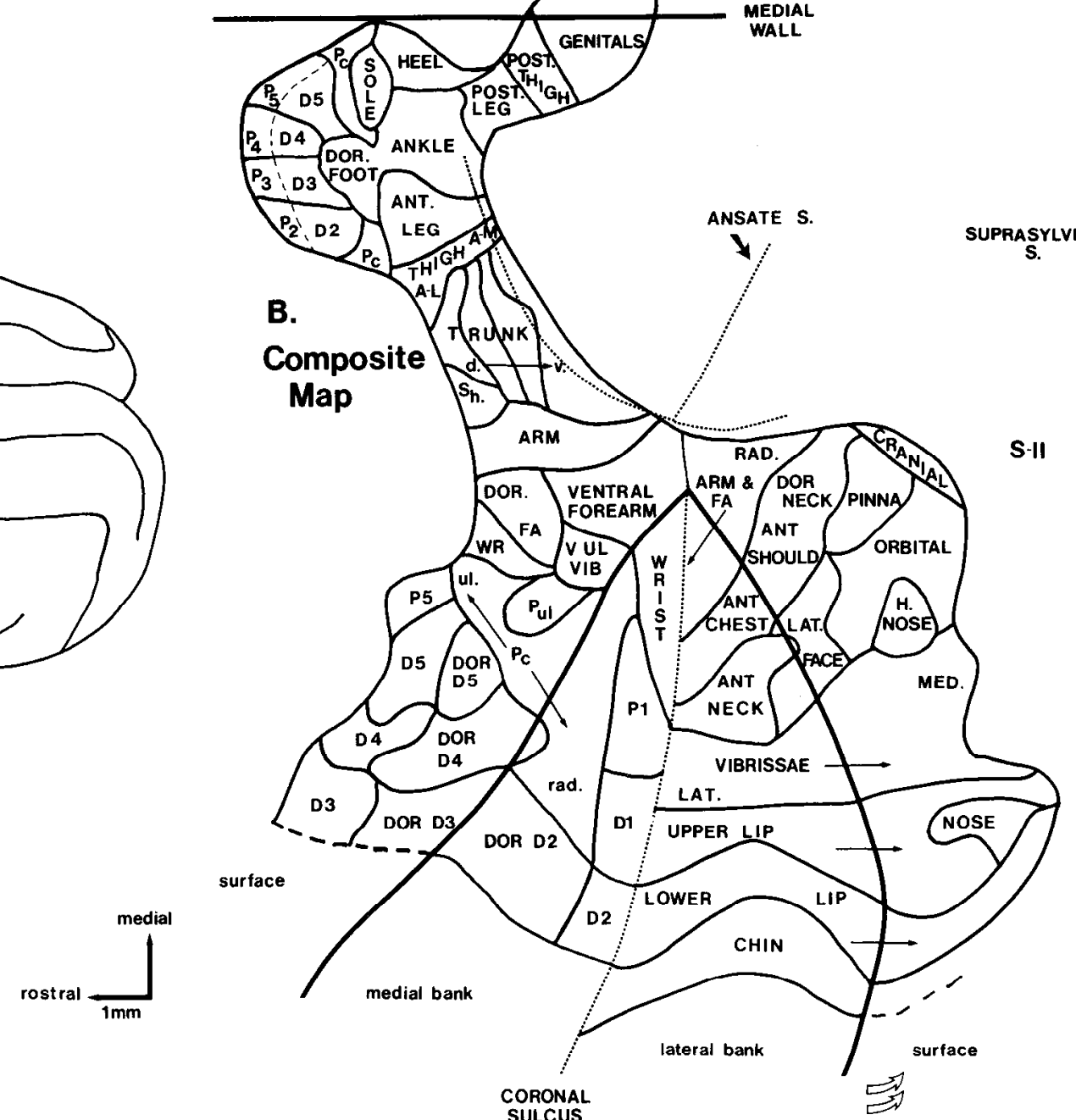

Figure 2. The representation of the body surface in SI in the cat. The location of S-I is indicated by shading on a dorsolateral view of the brain in $A$. The composite map was generated by combining three cases which together explored almost the full exlent of SI. The coronal sulcus has been "opened." A portion of the map extends into the ansate sulcus, which is indicated by a fine dashed line. The heavy dashed lines in the forepaw and face region indicate where we were unable to determine the precise rostral border due to the extreme curvature of the brain and the difficulty in access to this region. Light dashed line in hindpaw region separates the region representing dorsal digits caudally from the ventral surfaces and claws. $P c$, large central pad and adjoining ventral surface of forepaw and hindpaw; $S h$, shoulder; Pul, ulnar pad at wrist, $H$. nose, hairy portion of nose; $W R$, wrist; $D_{1}$ to $D_{5}$, digits of limbs; $P_{1}$ to $P_{5}$, glabrous digil pads; $d . \rightarrow v$., dorsal to ventral.

cutaneous stimuli were in area 3 a rather than somatic koniocortex.

The caudal border of S-I was more difficult to determine. At least part of caudal S-I adjoined other cutaneous sensory fields. As other investigators have determined (Woolsey and Fairman, 1946; Berman, 1961; Haight, 1972; Burton et al., 1982), the head representation of SI joins the head representation of S-II along the caudolateral border of S-I. Since neurons in S-II were responsive to cutaneous stimuli, a change in submodality could not be used to define this border. Instead, S-II was distinguished from S-I by a change in somatotopic patterns with a reversal in organization along the border and an increase in receptive field sizes for neurons in SII. Because the border regions of S-I and S-II were somatotopically congruent (see Nelson et al., 1979), it is possible that minor errors were made in assigning re- cording sites along the border to the wrong representation.

More medial portions of caudal S-I were adjoined by one or more somatosensory fields that we will tentatively call "S-III." A third somatosensory field caudal to S-I has been identified by a number of investigators (Marshall et al., 1941; Tasker, 1960; Darian-Smith et al., 1966; Dykes et al., 1977; Tanji et al., 1978; Waters et al., 1982; Garraghty et al., 1983), but its full extent and organization are not yet known, and the possibility remains that sensory areas in addition to S-II and S-III border S-I caudally. As for S-II, recording sites that responded to cutaneous stimuli on body parts that were already represented in S-I were judged to be outside S-I, perhaps in S-III. Neurons in the presumptive region of S-III typically had larger receptive fields and were more difficult to drive than neurons in S-I. Under our anesthetic con- 
ditions, recording sites in the "S-III" region were sometimes unresponsive, and the caudal border of S-I could be determined by a sudden change in responsiveness. However, it remains possible that a few recording sites have been misassigned.

The border of the narrow medial margin of S-I was defined by a lack of responsiveness to low threshold cutaneous stimuli. Because S-I typically extended to or onto the medial wall, the full medial extent of S-I was sometimes difficult to determine. Electrode penetrations down the medial wall of the cerebral hemisphere could miss the most responsive layers of cortex, and large blood vessels covered portions of medial cortex. Sometimes representations of body parts including the tail and posterior thigh were not identified (compare Figures 1 and 2), indicating that the full medial extent of S-I was not always mapped.

The full rostrolateral extent of S-I was not determined. This region of S-I was difficult to map because of its poor accessibility and because it represented the oral cavity, which was inconvenient for detailed determination of receptive fields. Because determining the full rostrolateral extent of S-I was not critical for the issues of the present investigation, this region was not completely mapped.

The location, extent, and internal organization of the single cutaneous representation that we have defined as S-I are shown in Figures 1 and 2. S-I includes a large region of postcruciate cortex. Although there is variation in the pattern of sulci in this region in cats (e.g., Otsuka and Hassler, 1962; Kawamara, 1971), it is possible to describe the typical relation of S-I to sulci and gyri. In general, the trunk, hindlimb, and proximal arm representations in S-I occupied a portion of the posterior sigmoid gyrus between the postcruciate "dimple" rostrally and the ansate sulcus caudally. Medially, the representation of the hindpaw extended rostrally and typically approached the lip of the cruciate sulcus. On some occasions, the hindpaw representation extended onto the medial wall of the hemisphere, and the postaxial hindlimb was found represented medial and caudal to the hindpaw. The forearm was represented adjacent to the arm on the lateral aspect of the posterior sigmoid gyrus and on the coronal gyrus and within the coronal sulcus. The representations of the face, neck, and head were found on the coronal gyrus and lateral bank of the coronal sulcus.

In the following sections, the organization of the representations of the various body surfaces is examined in detail. In addition, the representation is related to cortical cytoarchitecture. Experimental evidence is given for two basic conclusions. First, the body surface is represented only once in a highly topographic manner in S-I of cats. Second, this representation extends over cortex that contains most or all of the architectonic fields, $3 \mathrm{~b}$, 1, and 2 of Hassler and Muhs-Clement (1964).

Representation of the trunk. The region of cortex representing the trunk was extensively mapped in six cats. The trunk representation occupied a band of cortex on the posterior sigmoid gyrus bordered rostrally by the postcruciate "dimple" and caudally by the medial part of the ansate sulcus (Fig. 1). The S-I map was most narrow in this region, often extending only 2 to $3 \mathrm{~mm}$ in rostrocaudal extent and often extending approximately $1 \mathrm{~mm}$ down the anterior bank of the ansate sulcus. The representation of the trunk was oriented with the dorsum rostral and more lateral and ventral surfaces progressively more caudal within S-I. The groin and dorsal hip were represented most medially in this region, and rostral trunk surfaces were represented laterally. Thus, the dorsal shoulder was represented lateral to the dorsal trunk at the rostrolateral border of the S-I trunk region. Similarly, the ventral chest at the ventral arm was reprcsented caudally, where it formed the caudolateral border of the trunk representation.

Figure 3 illustrates the location, extent, and topographic order of the representation of trunk in S-I of a typical case (80-113). Recording sites 1 to 6 , extending from the rostral to caudal borders of S-I, demonstrate a single continuous sequence of receptive fields whose locations shifted from the dorsal midline to the lateral trunk and onto the ventral trunk midline. In this and all cases, a single continuous topographic representation of the trunk was found in a back-to-belly sequence from rostral to caudal in the S-I cortex.

Representation of the hindlimb and tail. The hindlimb was represented medial to the representation of the trunk near the medial end of the ansate sulcus (Fig. 1). It typically extended rostrally toward the lip of the cruciate sulcus and medially toward and occasionally onto the medial wall of the hemisphere. In general, the hindpaw was represented rostral to more proximal hindlimb surfaces. Overall, the hindlimb representation was oriented with the anteromedial and anterolateral surfaces of the thigh adjacent to the ventral and dorsal trunk, respectively. Posterior portions of the hindlimb were represented more medially and often split into two locations, one laterally in the hindlimb region and the other extending caudomedially toward the representation of the tail and genitalia. Caudally, the representations of the ankle and leg partially surrounded that of the hindpaw. In general, the medial ankle and leg were represented laterally, and the lateral ankle and leg were represented caudomedially.

Figure 4 illustrates the extent and organization of the representation of the lateral surfaces of the hindlimb, hip, and tail. The illustrated sequence of recording sites (1 to 11) corresponded to a continuous progression of receptive fields from the base of the tail, along the posterior aspect of the hindlimb, across the anterior ankle and lateral foot to the anterolateral margin of the leg up to the knee. Recording sites 1 and 2 showed receptive fields on the base of the tail. More distal parts of the tail were found for recording sites in depth penetrations down the medial wall. The genitalia were represented in a small region of cortex near the representation of the base of the tail.

In one cat a somewhat different organization of the representation of the thigh was noted. Figurc 5 illustrates the cortical map derived from the mapping data of cat 80-130. This map differs from the one shown previously in that the most medial and rostral portion of the 

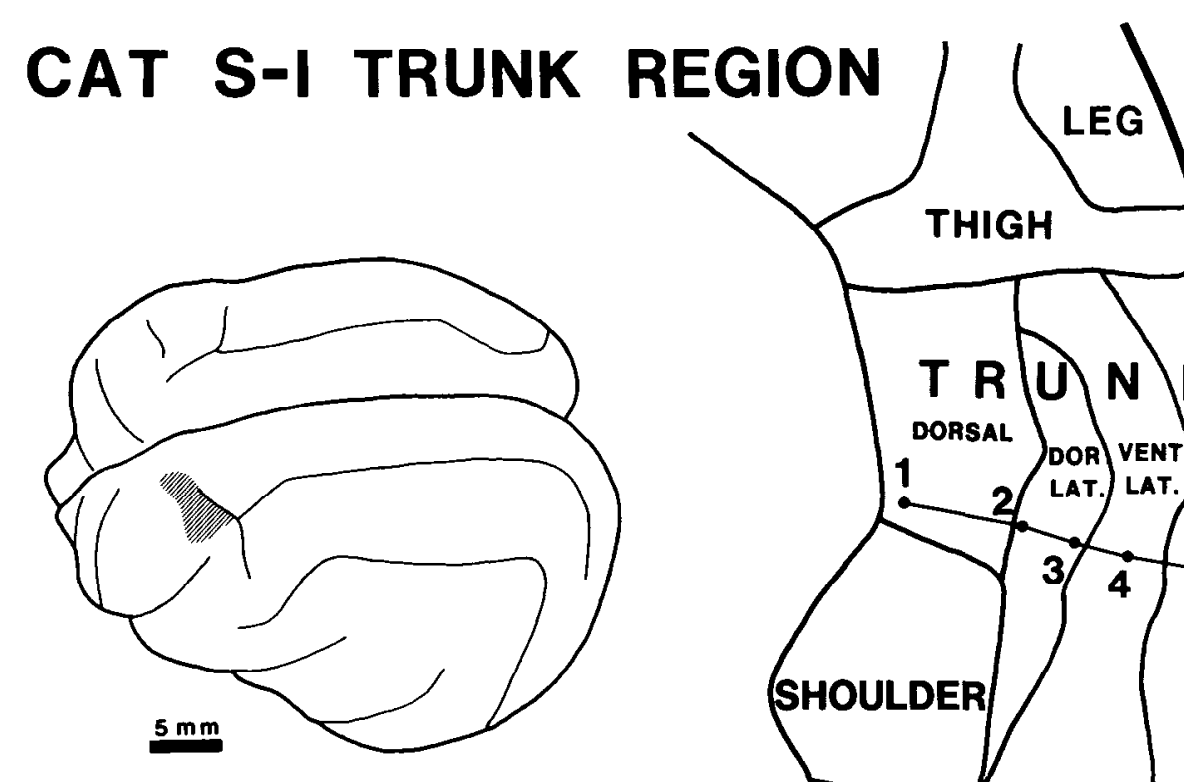

THIGH

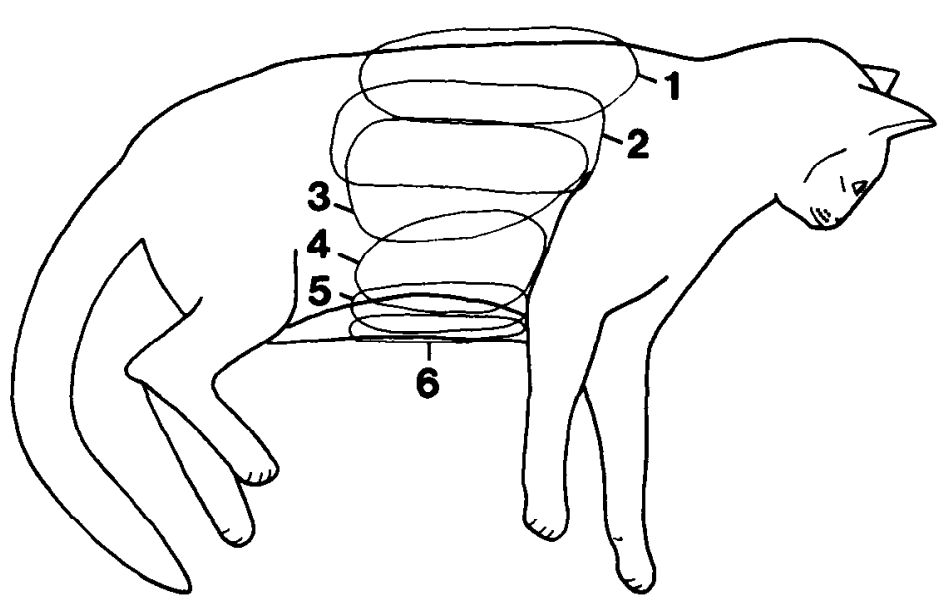

80-113

Figure 3. Representation of the trunk in S-I. Upper left, Surface view of brain indicating the portion of S-I that was mapped. Upper right, Cortical map generated from the data in this case (80-113). A row of recording sites ( 1 to 6 ) extends from rostral to caudal across cortex. Lower, Location of receptive fields corresponding to the recording sites illustrated above. The dorsal trunk is represented rostrally in S-I, and the ventral trunk is represented caudally. The chest is represented lateral to the abdomen.

hindlimb representation includes dorsal hip and lateral posterior aspect of the thigh. This relative location in cortex typically represented the anterolateral rather than the posterolateral thigh. The sequence of recording sites in Figure 5 indicates the topological order of the representation of the thigh in this case. A single continuous representation of the thigh extended from the dorsal trunk onto the dorsal hip and lateral posterior thigh, and then onto the anterolateral, anteromedial, and finally onto the posteromedial thigh surfaces.

Representation of the hindpaw. In general, the hindpaw was represented rostral to that of the more proximal hindlimb surfaces. The representation of the hindpaw was characterized by a central region devoted to the dorsal foot and proximal dorsal digits, a more medial region which represented most of the sole and heel, and a large region which represented the digits. Often the representation of the hindpaw digits approached the lip of the cruciate sulcus (Figs. 1 and 6), but in some cases the hindpaw representation was rotated medially and extended onto the medial wall of the hemisphere.

The organization of the representation of the hindpaw in S-I of cat 81-79 is illustrated in Figure 6. Three rows of recording sites indicate basic features of the hindpaw representation. Row $A$ is a sequence of recording sites (1 to 7) extending across the representation of the hindpaw digits. The sequence of receptive fields encountered for row A progressed from the lateral side of digit 5 to the medial side of digit 2. The representations of the dorsal digits and the hair tufts between digits were continuous with the more caudally located representation of the dorsal foot. These prominent hair tufts had relatively large areas of representation within S-I. Cortex rostral to the representation of these hair tufts represented the corresponding digit pads. The proximal ventral surfaces of the digits and the skin webs between the digits were 


\section{CAT S-I HINDLIMB AND TAIL}

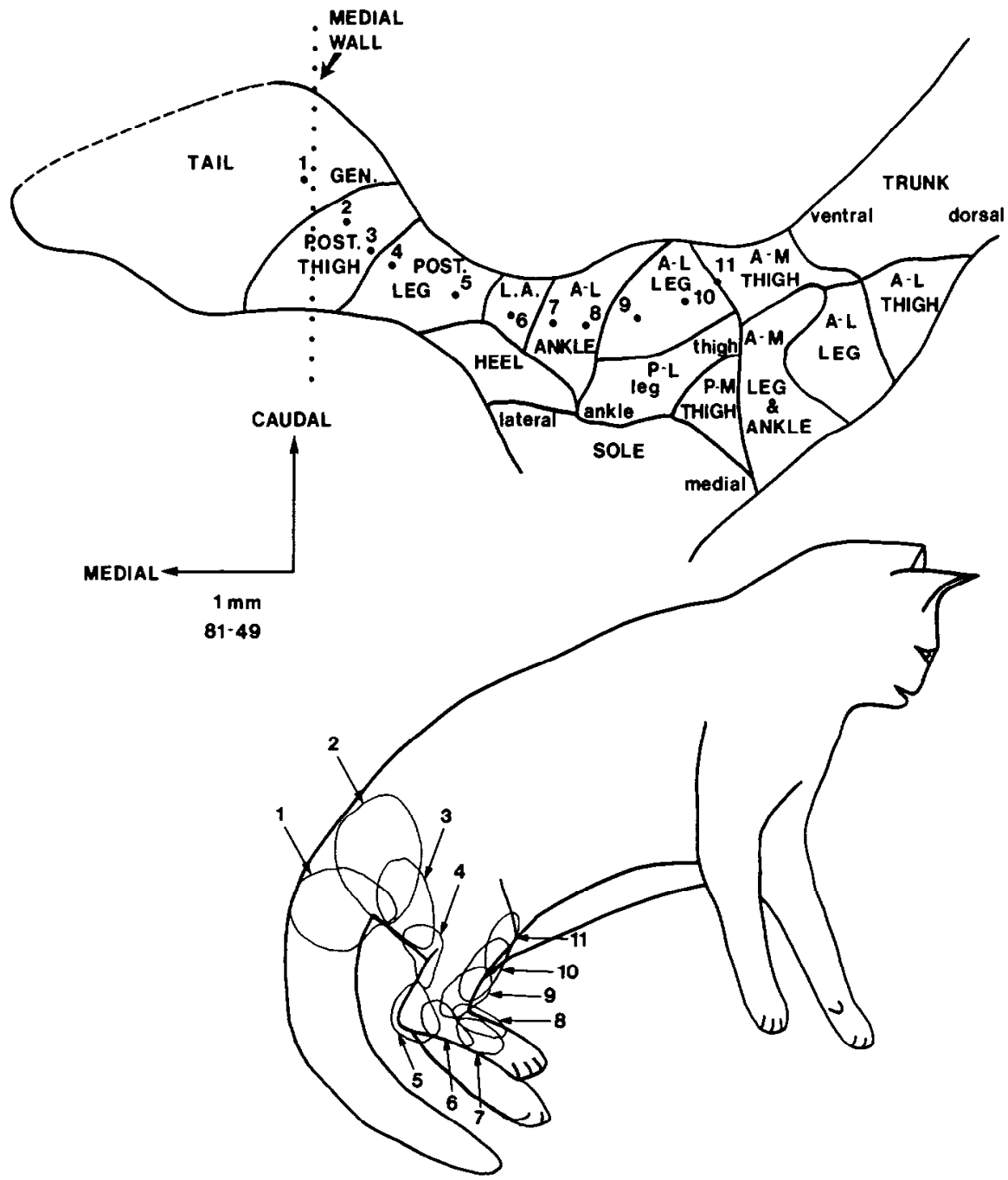

Figure 4. Representation of the hindlimb and tail. Above, Partial cortical map extending from the representation of the caudal trunk on the medial wall of the hemisphere (indicated by dotted line). A row of recording sites ( 1 to 11) along the caudal aspect of S-I demonstrates a single continuous representation from the proximal tail to anterior knee. Below, Receptive fields corresponding to the recording sites above. $A-L$, anterior-lateral; $A-M$, anterior-medial; $P-L$, posterior-lateral; $P-M$, posterior-medial.

found in small regions of cortex adjacent to the representations of the digit pads. The skin around the claws was represented most rostrally, where cells tended to demonstrate an exquisite sensitivity to light stimulation. Recording sites just rostral to this region also demonstrated sensitivity to stimulation of the claws, but these responses were of higher threshold than those seen more caudally in S-I. Nevertheless, it was sometimes difficult to draw a rostral border of S-I in this region and be confident that portions of area 3 a were not also included.

Row B (Fig. 6) includes nine recording sites extending across the mediolateral width of the hindpaw representation just rostral to the representation of the ankle. The corresponding sequence of receptive fields shifted systematically from the central pad to the dorsolateral foot, across the dorsal foot to its dorsomedial margin, and back onto the plantar surface near the medial central pad. Thus, this sequence of recording sites described a single continuous progression around the distal hindpaw just proximal to the digits. An interesting aspect of this organization is the split of the distal ventral foot at the medial central pad. Thus, lateral and medial parts of the ventral foot may be represented at medial and lateral sides of the prominent dorsal foot representation.

The remaining ventral surfaces of the hindpaw were represented caudally and medially where the central pad provided continuity of digit 5 with the more proximal sole and heel. Row C in Figure 6 demonstrates a sequence of recording sites through the small region which represented the ventral heel and sole. The corresponding receptive field sequence illustrates a single orderly representation of the foot with the lateral heel and sole medially in cortex to the medial heel and sole. The representation of most proximal hindpaw surfaces pro- 


\section{CAT S I THIGH REPRESENTATION}

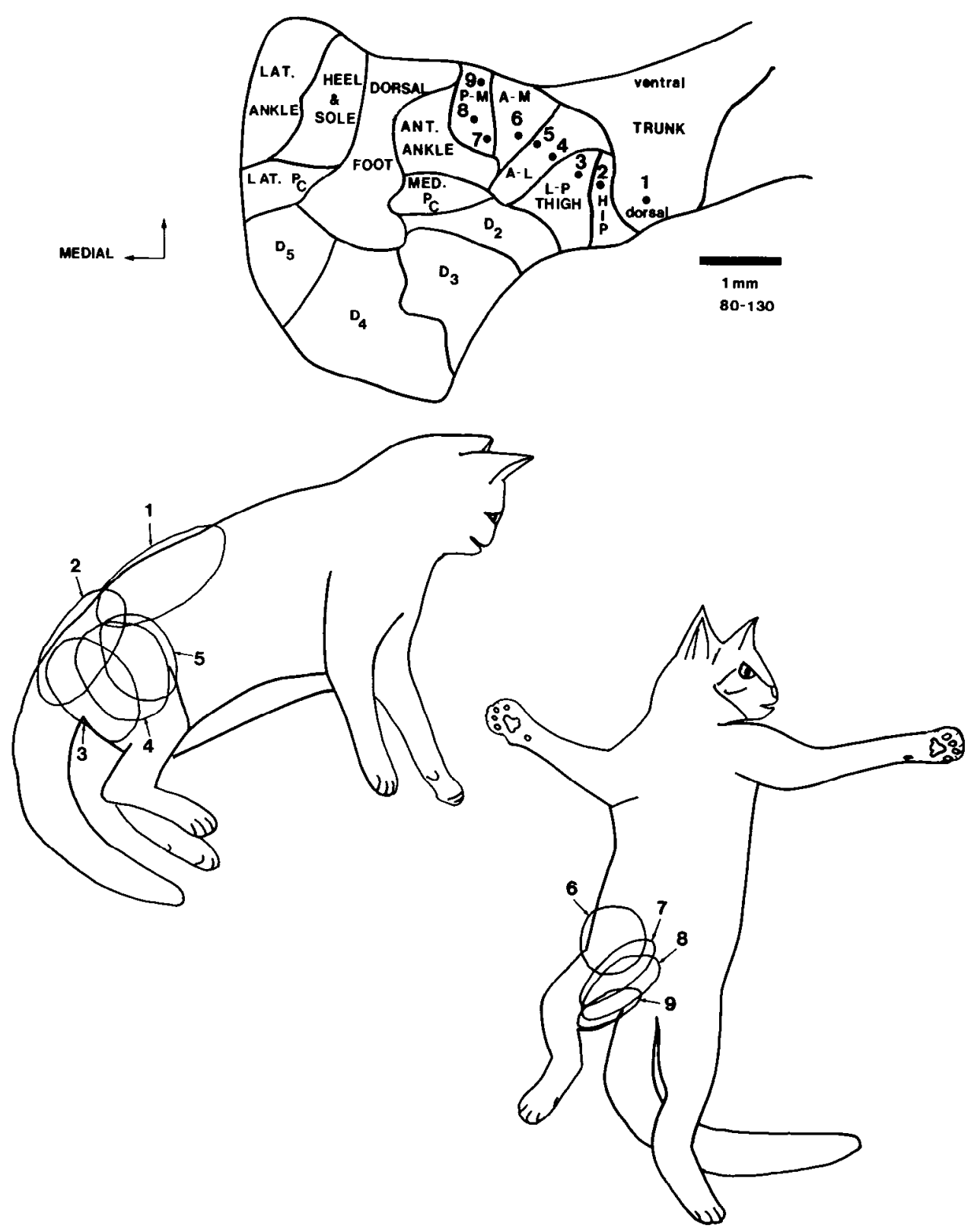

Figure 5. Variation in the representation of the thigh in S-I. Cortical map of the hindlimb and trunk region of cat 80-130 indicating a row of recording sites (1 to 9 ) extending from rostrolateral to caudal-medial in cortex. The corresponding receptive fields are indicated below and demonstrate a single continuous representation of the thigh with the dorsal caudal hip represented adjacent to the dorsal trunk. Receptive fields shift in location from the dorsal hip, to the lateral posterior thigh, across the anterior lateral thigh to the anterior medial and finally posterior medial thigh. Compare with Figures 2 and 4, where the anterior lateral thigh is represented adjacent to the dorsal trunk.

vided topographic continuity with the ankle representation.

Representation of the arm and forearm. The arm and forearm were found lateral to the representation of the trunk in cortex typically extending from the ansate sulcus medially to the coronal sulcus. In addition, a small portion of the radial arm often extended onto the coronal gyrus. The organization of the body surface map for the coronal gyrus is described in a subsequent section. The representation of the arm and forearm was organized with the dorsolateral shoulder and forelimb rostral and the ventral arm caudal. This orientation allowed continuity with the representation of the rostral trunk. Thus, the dorsal trunk midline, dorsal shoulder (posterior as- 


\section{CAT S I HINDPAW REPRESENTATION}
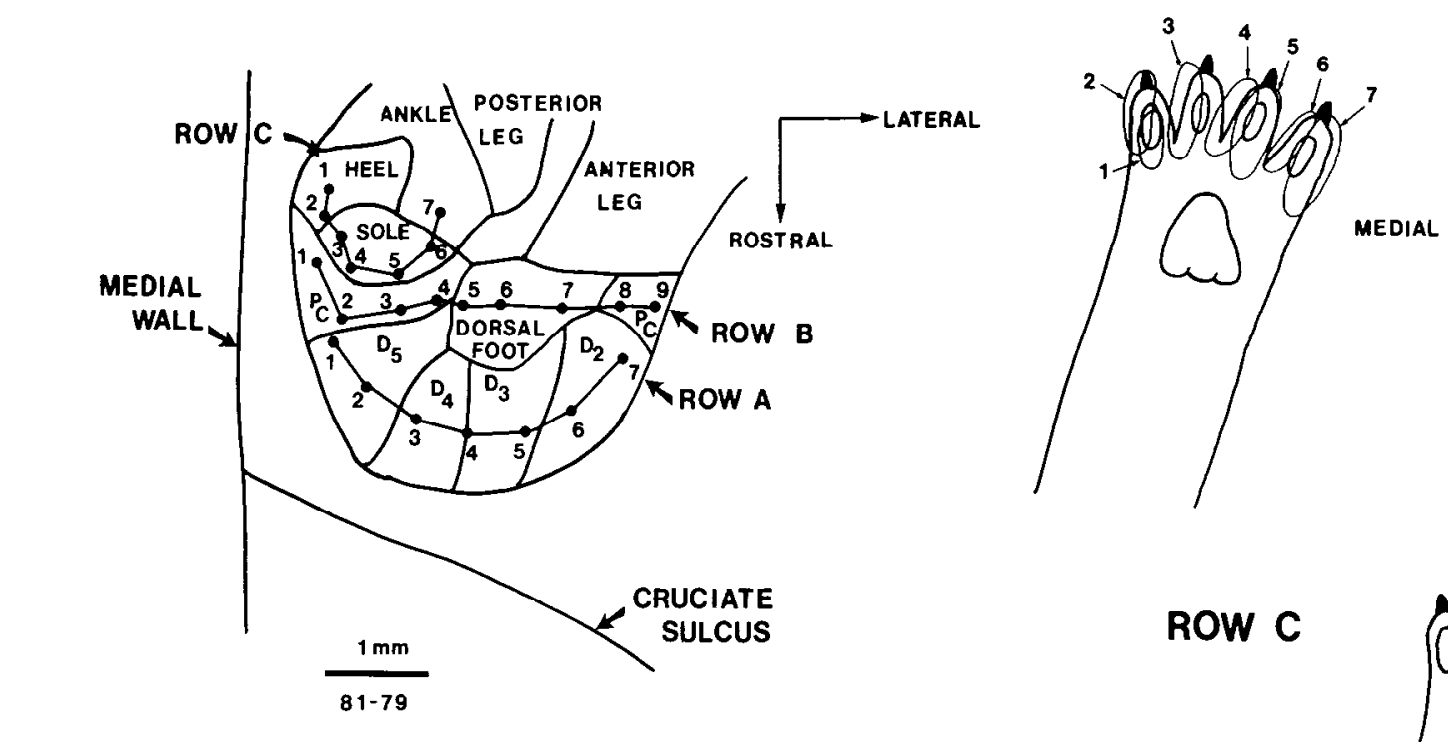

\section{ROW A}
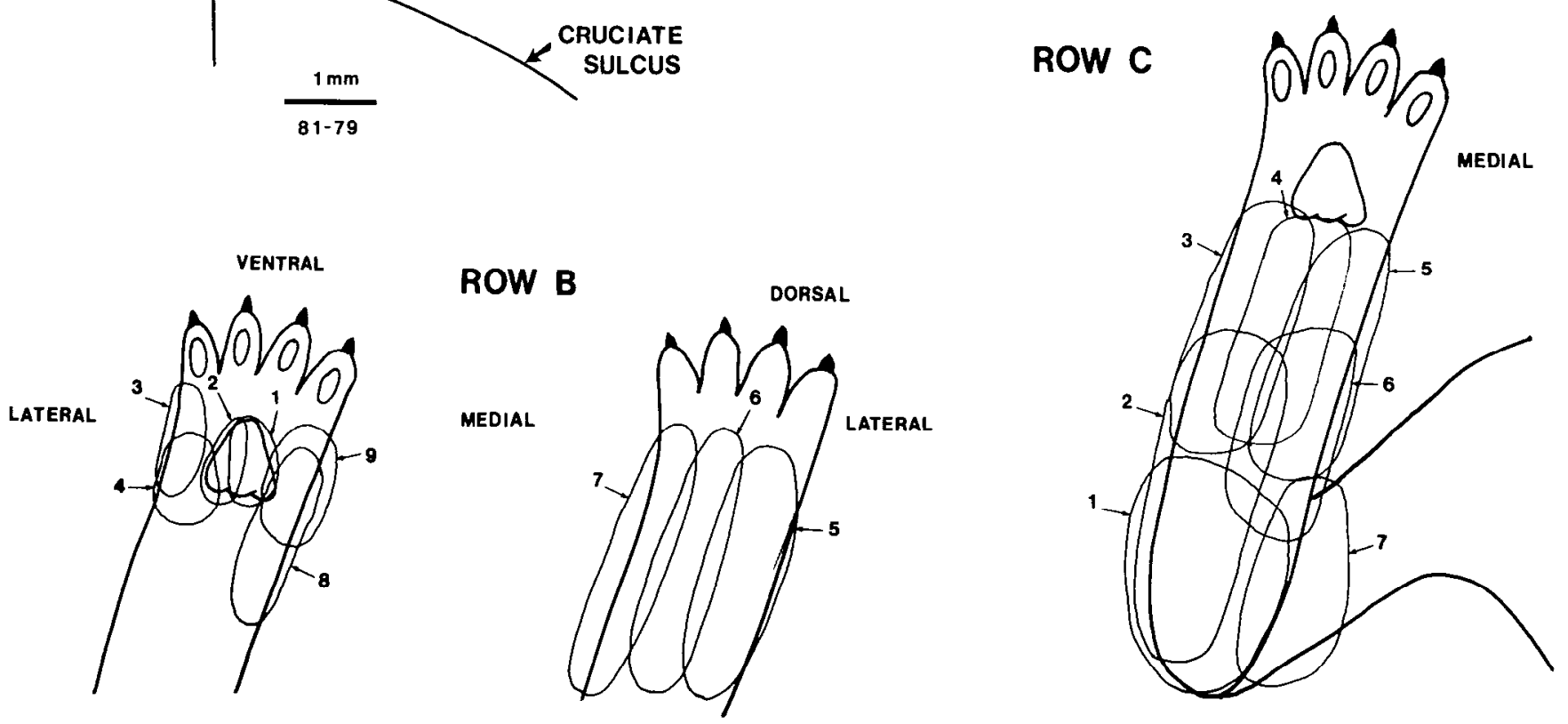

Figure 6. Representation of the hindpaw. Three rows of recording sites demonstrate the topographic relations among the parts of the hindpaw and surfaces of the hindlimb. $P c$, central pad and adjacent ventral foot. $D_{2}$ to $D_{5}$, digits of limbs.

pect), and lateral arm were found along the rostral border of S-I. The ventral arm was represented more caudally next to the representation of the chest and axilla. Laterally, the rostral border of S-I turned sharply forward into the coronal sulcus, where more distal surfaces of the forelimb and the forepaw were represented.

Figure 7 illustrates the organization of the representation of the forelimb in cat 80-113. A sequence of recording sites (row $A, 1$ to 6 ), extending from rostral to caudal along the trunk-arm border region, resulted in a receptive field sequence from the lateral aspect of the proximal arm to the posterolateral arm and onto ventral arm. A sequence of recording sites (row $B, 1$ to 6), extending from medial to lateral across the S-I forearm representation, resulted in a sequence of receptive field locations that shifted from the dorsal to ventroradial forearm by way of the ulnar margin. The orientation of the forearm representation provided topographic continuity with the greatly enlarged representation of the forepaw. Thus, the distal ulnar forearm was represented along the rostromedial border of S-I, and the radial forearm was represented in more lateral and posterior cortex extending onto the medial and lateral banks of the coronal sulcus. Overall, the representation of the arm and forearm was highly somatotopic within the regions which are not disrupted by the "splitting" of the forelimb along its radial margin. This "splitting" of the forelimb allows for the topographic adjacency of forearm, wrist, and forepaw. The radial margin of the arm was typically found in the ansate sulcus near the representation of the anterior shoulder and neck, as shown in Figure 9.

Various parts of the forelimb were found to have different magnifications in cortex. Most notably in all cases a small cluster of vibrissae on the ventral ulnar wrist activated a large expanse of cortex.

Representation of the forepaw. The forepaw was represented mainly rostral and lateral to the more proximal forelimb. In general, the representation of skin around the claws formed the rostral border of S-I in this region. This border extended from an anterior location on the crown of the anterior sigmoid gyrus, medially, and onto the medial wall of the coronal sulcus. As far as we could 

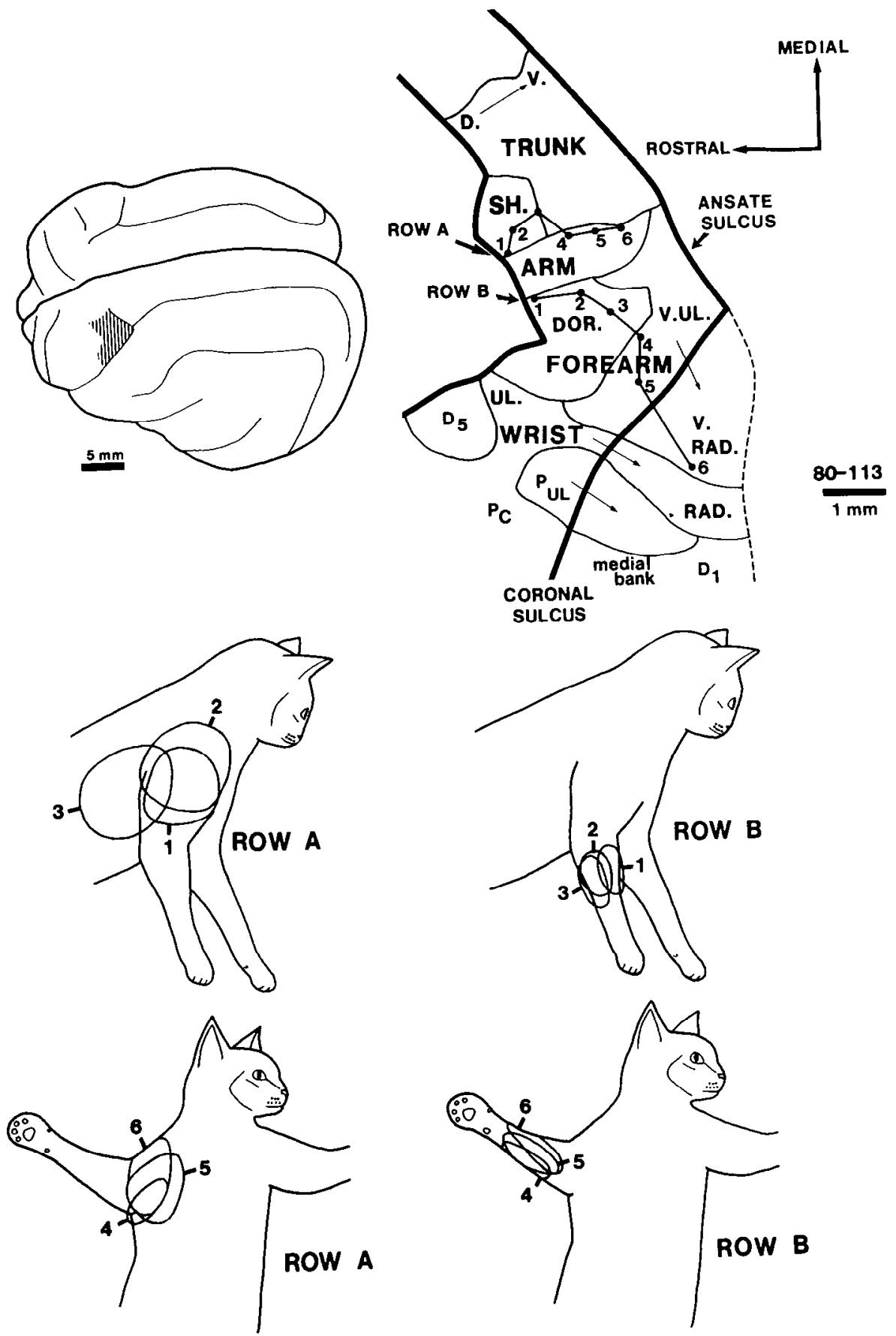

Figure 7. Representation of the arm and forearm. The region of corlex examined is shaded on the surface view of the brain at the upper left. The detailed cortical map is shown at the right with two rows of recording sites. Row $A$ (1 to 6) traverses the representation of the arm, and the corresponding receptive fields are indicated at the lower left. Row $B$ traverses the representation of the forearm from the dorsal aspect to the ventroradial aspect. The corresponding receptive fields are illustrated at the lower right. UL., ulnar; RAD., radial. Other abbreviations as in Figures 1 and 2.

determine, cortex near the fundus of the coronal sulcus formed the lateral border of the forepaw representation. Immediately adjacent cortex on the lateral bank of the coronal sulcus represented the face. The rostral and medial boundaries of S-I in this region were indicated by an increase in the response threshold of neurons or by clear indications of a switch in modality from cutaneous to "deep" excitatory drive. Typically we did not attempt to explore completely the most rostral portions of S-I in this region, primarily due to the extreme curvature of the cortex. Furthermore, we did not record from the anterior portions of the fundus of the coronal sulcus and thus do not know if cortex devoted to "deep" receptors extends laterally to encompass $\mathrm{D}_{2}$ and $\mathrm{D}_{1}$.

The representation of the forepaw in S-I was oriented with the ulnar forepaw most medial, and more radial 
forepaw surfaces progressively more lateral and into the depths of the coronal sulcus. Overall, the forepaw region was organized in a radial pattern with the digit pad and claw representations forming the perimeter. The forepaw representation was characterized by a large representation of the dorsal paw which was continuous with the large representation of the hair tufts of the digits. A large expanse of cortex was devoted to the glabrous central pad (Pc). In accordance with the other forepaw surfaces, the ulnar side of the central pad was represented medially on the anterior sigmoid gyrus, and the radial side was represented laterally in cortex on the medial wall of the coronal sulcus.

Figure 8 illustrates the organization of the represen-
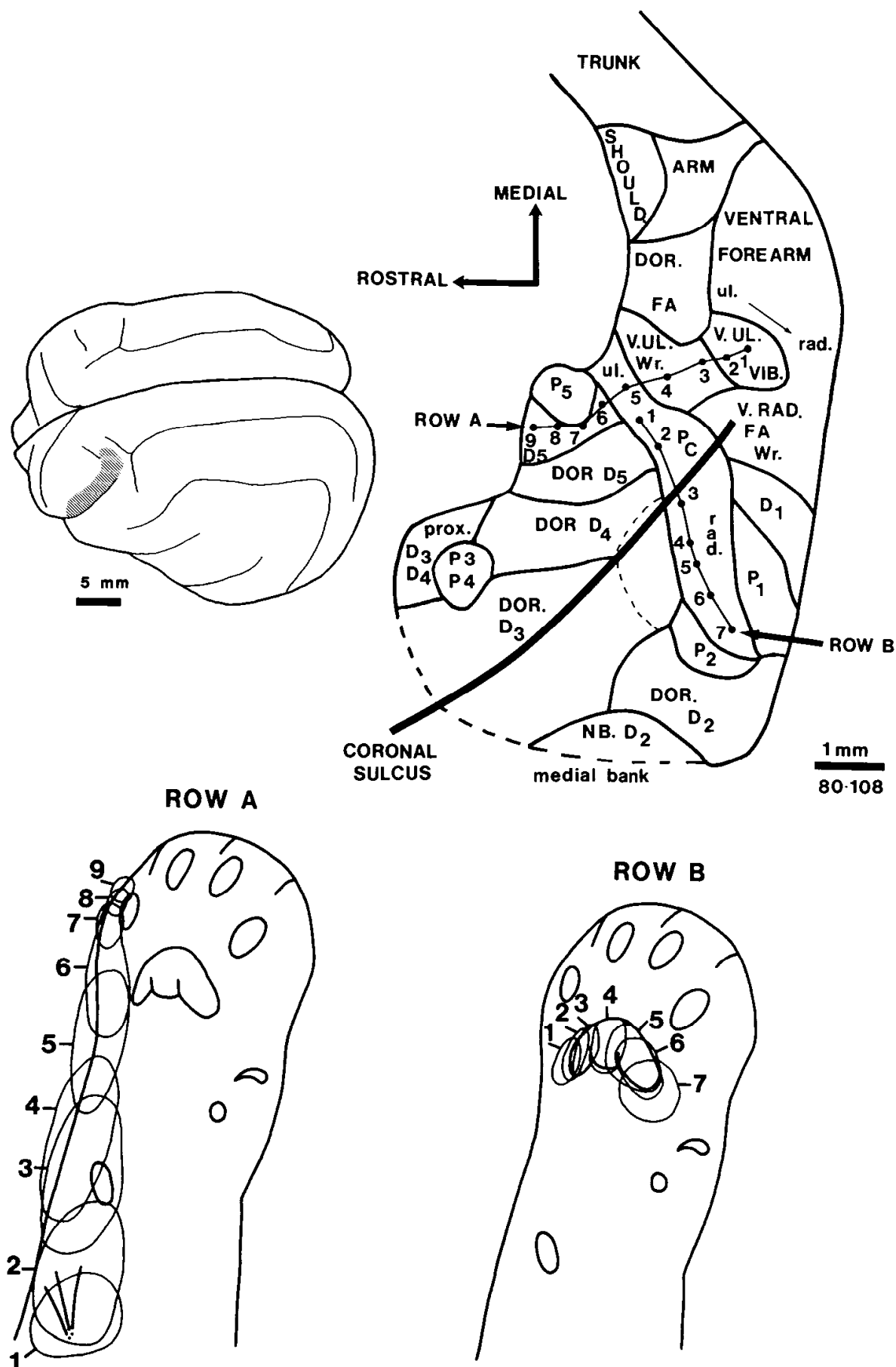

Figure 8. Representation of forepaw. The region of cortex investigated is shaded on the surface view of the brain at the upper left. Row $A$ (1 to 9) illustrates the proximodistal orientation of the forepaw representation. Row $B$ ( 1 to 7 ) illustrates the ulnar to radial organization of the forepaw at the level of the large central pad. In general, the forepaw digits are represented in a radial fashion around the representation of the central pad. $V$. Ul. VIB., vibrissae located at the ventral ulnar wrist; $N B . D_{2}$, nailbed of digit 2. This map was not extended rostrally to include the locations of the representation of the remaining claws. Abbreviations as in Figures 1 and 2. 
tation of the forepaw of cat 80-108. The general proximal to distal axis along the ulnar forepaw is illustrated in row $A$, where recording sites 1 to 9 extend from caudal to rostral and display receptive fields whose locations shifted from the ventroulnar vibrissac of the wrist, up the ulnar margin of the forepaw to the ulnar surface of digit 5. The medial to lateral organization of the S-I forepaw region is illustrated in row $B$. The receptive field at site 1 was located on the ulnar side of the central pad; progressively more lateral recording sites had receptive fields which shifted from ulnar to radial across the central pad.

The glabrous digit pads and proximal ventral digits were represented in somewhat variable positions. In case 80-108 (Fig. 8), pad 2 was represented just rostral to the radial central pad and pads 3 and 4 were represented rostromedially, bordered caudally by the representations of proximal digits 3 and 4 . Pad 5 was along the medial margin of the representation of digil 5. Overall, it appeared that the representations of the digit pads and the proximal ventral digits were displaced by the larger representation of the dorsal paw and interdigit hair tufts. This displacement resulted in a disruption of topographic continuity.

In many respects, the organization of the forepaw shared similarities with the representation of the handpaw. Both paw representations were dominated by a large expanse of tissue representing the dorsal paw, dorsal digits, and hair tufts between digits. Both the hindpaw and the forepaw representations were bordered rostrally by the representation of skin surrounding the claws. The representations of the hindpaw and forepaw did differ, however, in regard to the representation of the central pad $(\mathrm{Pc})$ as well as with the topographic adjacencies with their respective proximal limb surfaces. Thus, in the hindpaw we commonly found a portion of the central pad represented lateral to the remainder of the central pad representation and split off from it by the representation of the dorsal foot. In the forepaw region, the large central pad was typically represented across the full mediolateral width of the forepaw representation and it was not disrupted by the dorsal paw representation. Instead, the dorsal paw was represented rostral to the central pad, and thus a major discontinuity was introduced into the forepaw map just distal to the central pad. Topographic continuity was preserved with the ulnar portions of the forelimb by the representation of the margin of the ulnar forepaw and the adjacent ulnar margin of digit 5 . In regard to continuity with proximal limb regions, the forepaw had different topographic adjacencies than were seen for the hindpaw. Thus a major portion of the forepaw representation was devoted to the ventral and particularly ulnar aspects of the forepaw and wrist, where it maintained topographic adjacency with the large central pad. In contrast, only a small portion of the hindpaw representation permitted continuity of the sole and heel with more distal ventral paw surfaces, and much of the representation instead involves the continuity of the representation from medial and lateral ankle onto dorsal foot and heel, respectively.

Representation of the radial wrist, forearm, anterior arm, and shoulder. A portion of the anterior shoulder, arm, and chest, as well as a portion of the radial forearm, was not found medial to the forepaw representation with the remaining trunk and arm surfaces. Instead, the representation of these skin regions was found in a strip of cortex along the posterolateral border of S-I at the junction of the ansate and coronal sulci (Fig. 9). This small strip of cortex adjoined the distal forepaw representation and provided a topographic continuity between the forelimb and head representations. The representation of the most distal radial forelimb was usually buried in the posterior bank of the coronal sulcus. More proximal surfaces, including the anterior arm, anterior shoulder, and rostral chest, were represented in cortex of the lateral bank of the coronal sulcus.

The organization of this lateral region of cortex is shown in Figure 9. Recording sites 1 to 9, which extended from the lateral bank of the coronal sulcus onto the coronal gyrus, demonstrated receptive fields that progressed up the radial wrist, forearm, anterior arm, anterior shoulder, and adjacent lateral neck. These representations thus provided continuity of the anterior chest and neck representation with the lateral face.

Representation of the head and face. The head and face were represented laterally in S-I, on the dorsomedial convexity of the coronal gyrus and lateral bank of the coronal sulcus. The dorsolateral neck and shoulder were represented caudally in this region, providing a topographic continuity with the dorsoradial forearm and anterior shoulder. The head representation was oriented with lateral skin surfaces most medial, extending onto the lateral bank of the coronal sulcus, and the midline of the head was represented laterally at the border of S-I. The mystacial vibrissae were represented in a sequence with the most dorsal vibrissae caudomedial and the most lateral vibrissae rostral in the coronal sulcus. In general, the lips were represented most rostrally, and cranial surfaces were represented caudally.

Figure 10 illustrates the organization of the representation of the face of cat 81-5. This experiment explored most of the S-I face region and provided evidence for the reversal in the representation of the head at the border of areas S-I and S-II. Two rows of recording sites are illustrated. The first row of recording siles (1 to 7) extended from the exposed coronal gyrus into the lateral bank of the coronal sulcus and demonstrated receptive fields that shifted from the midline of the forehead across the supraorbital skin to the lateral face and neck. The second row of more anterior recording sites (8 to 13) demonstrated receptive fields that shifted from the upper lip midline to the medial and lateral upper lip. The most. rostral and lateral portions of the face were not explored, and the lateral lip representation may extend quite a distance down the lateral bank of the coronal sulcus. The cortical representation of the oral cavity was not determined, but it is likely that oral surfaces are represented in cortex rostral to the lip representation. The hairy and glabrous parts of the nose were represented separately in S-I. The hairy nose was found adjacent to infraorbital skin and vibrissae, while the glabrous nose was represented next to the lips.

\section{The relation of $S-I$ to cortical cytoarchitecture}

In each mapping experiment, marker lesions were placed at selected recording sites, and the brain was 


\section{CAT S-I 81-5}
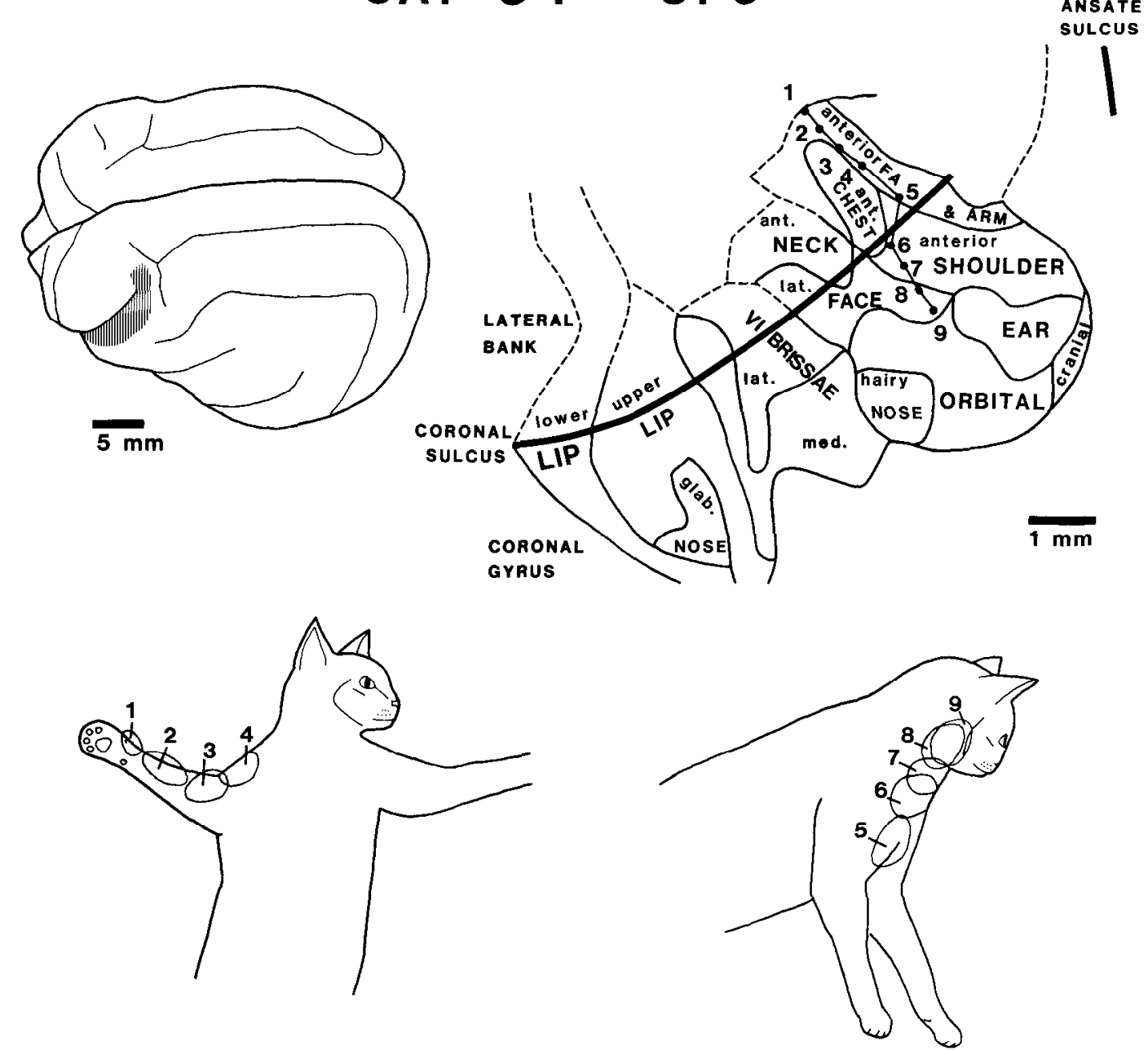

Figure 9. Representation of the anterior arm and radial forearm. The row of recording sites (1 to 9) demonstrates a sequence of receptive fields from the distal radial forelimb, up the radial aspect of the forelimb onto the anterior arm, anterior shoulder, onto the lateral aspect of the face.

typically cut in the parasagittal plane. This allowed the electrophysiological results to be related to cortical cytoarchitecture over much of the mediolateral extent of S-I, but the plane of section was inappropriate for the most lateral portion of S-I. Within the region that was suitable for study, S-I appeared to coincide with a fairly homogeneous architectonic field with distinct architectonic boundaries rostrally and caudally.

The main architectonic features of S-I are apparent in Figure 11, which is a brain section through a portion of S-I just medial to the coronal sulcus where the arm and forearm are represented. The S-I cortex is most clearly characterized by a merging of the dense granular and supragranular layers. In the section shown, layer $\mathrm{V}$ has few pyramidal cells, but this is a feature that varies by location in S-I cortex. More medially, as noted by Sanides and Hoffmann (1969), the portion of S-I representing the leg has more of the larger pyramidal cells. More laterally in the portion of S-I representing the forepaw, layer IV appears more distinct and more granular. Many current investigators would subdivide the S-I field shown in Figure 11 into areas $3 \mathrm{~b}, 1$, and 2 in a rostrocaudal sequence after Hassler and Muhs-Clement (1964). How- ever, such subdivisions within S-I do not appear to us to be justified. We prefer, instead, to use the term somatic koniocortex to specify S-I cortex, because this term has been used widely for S-I cortex in other species (see Kaas, 1983).

Distinct architectonic boundaries with fields adjoining S-I were usually apparent rostrally and caudally. The rostral border of S-I coincided with a cytoarchitectural change to area 3a of Hassler and Muhs-Clement (1964) or the intersensorimotor area of Sanides and Hoffmann (1969). Area 3a is characterized by a mixture of sensory and motor features, so that both large pyramidal cells in layer $\mathrm{V}$ and a moderately developed layer IV are apparent. In the brain section shown, the curvature of cortex compresses the supragranular layers of cortex, emphasizing the sensory features. Although no lesion identifies the S-I border with 3a in Figure 11, lesions were located at this border in several experiments (compare with Figs. 4 and 9 of Dykes et al., 1980b). Because of the pronounced sensory features of area 3a, as identified in Figure 11, some investigators might prefer to label some or all of the field as area $3 \mathrm{~b}$. The clear association of the field with noncutaneous inputs in the present experiments, 


\section{CAT S-I FACE REGION}
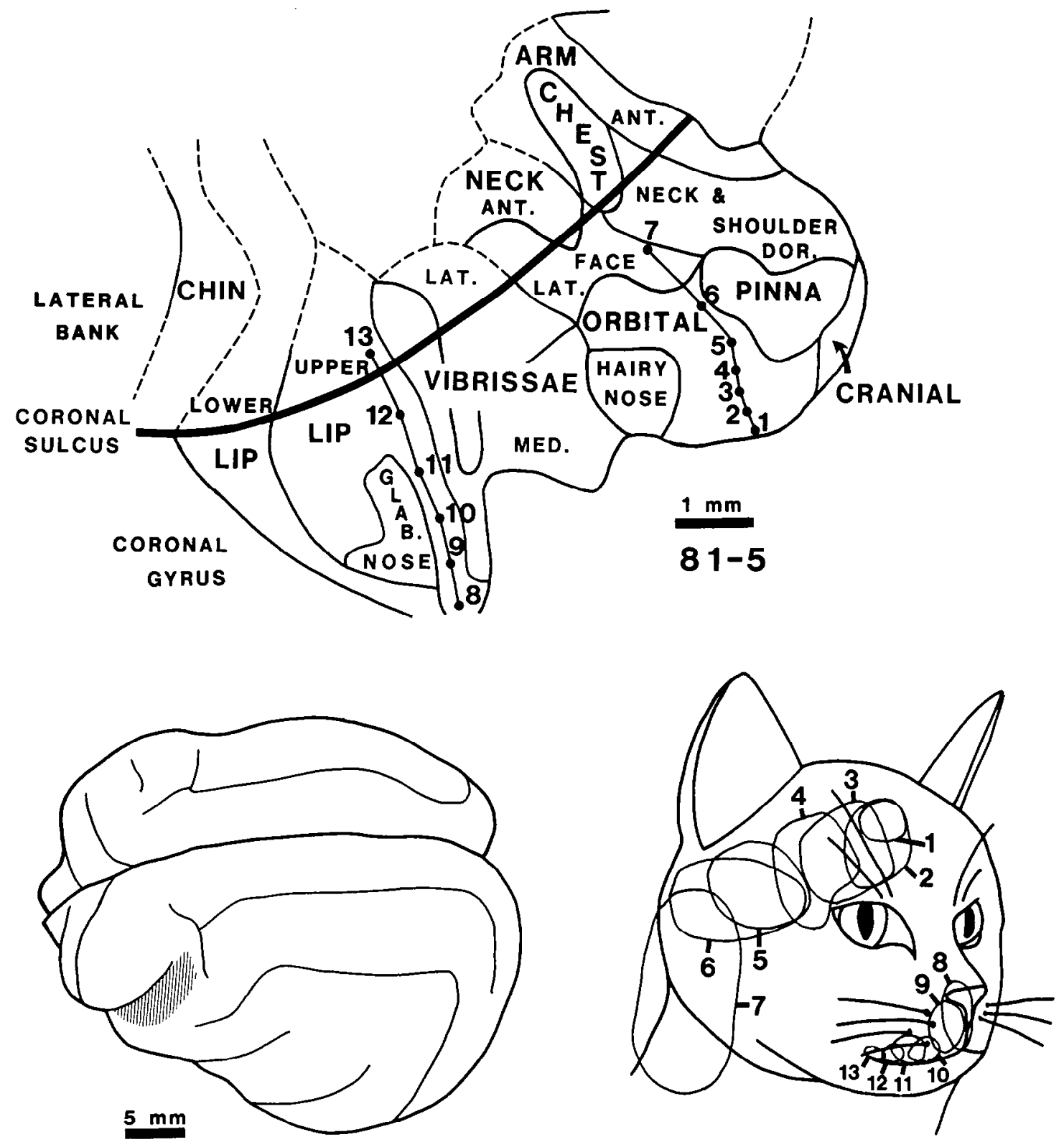

Figure 10. Representation of the head and face. Two rows of recording sites demonstrate sequences of receptive fields ( 1 to 7 ) from the supraorbital midline to the lateral face and ( 8 to 13$)$ from the midline upper lip to the corner of the mouth. Dashed lines indicate borders that were not defined precisely.

and those of Dykes et al. (1980b), argues against this interpretation.

The caudal border of S-I was indicated by cortex with less distinct lamination and an increase in layer $\mathrm{V}$ pyramidal cells. Sometimes the cortex just caudal to S-I was responsive to cutaneous stimuli. In the vertical electrode penetration leading to the marker lesion in Figure 11 , recordings in S-I were in the representation of the forearm. At the S-I border, a narrow unresponsive zone was followed by neurons first activated by stimulating digit 5 of the forepaw and then digit 4 . The lesion marks the location of recordings from tissue representing digit
4. This cortex may be part of the S-III representation (e.g., Tanji et al., 1978; Garraghty et al., 1983).

\section{Discussion}

In the present paper, the somatotopic organization of the first somatic area, S-I, of cats is described in detail, and a summary diagram indicates the expected locations and extents of body parts in the representation. This allows comparisons with the organization of S-I in other mammals and serves as a useful guide for future anatomical and physiological studies in cats. In addition, our results lead to several major conclusions. (1) The present 


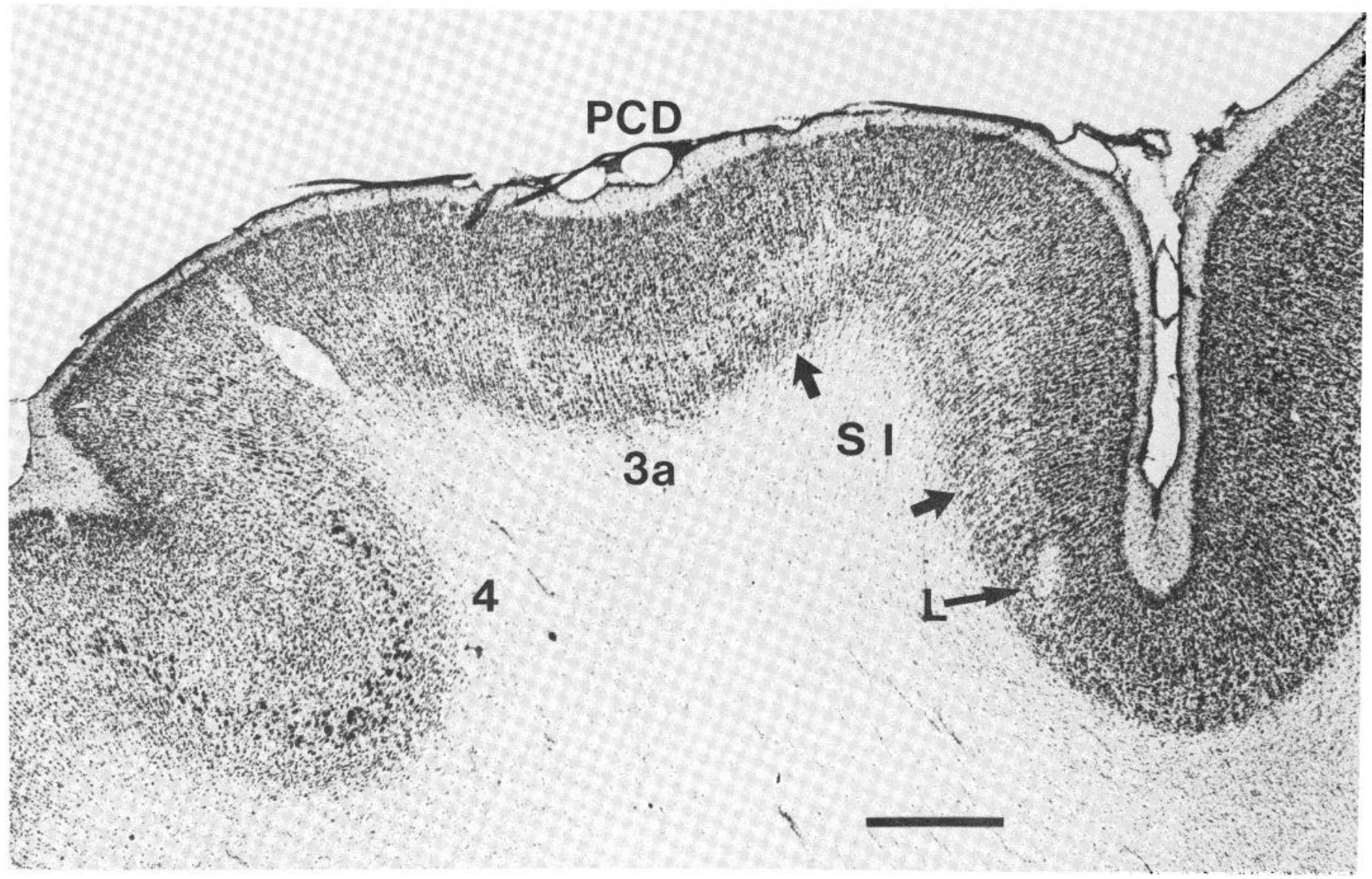

Figure 11. A parasagittal brain section through the region of S-I representing the forearm in case 80-113 (compare with Fig. 7). The rostral border of S-I corresponds to a transition in responses from those driven by cutaneous to those driven by deep receptors. The location of the section is similar to the section in Figure 9 of Dykes et al. (1980b) showing a physiological transition at the border of S-I (" $3 \mathrm{~b}$ ") with area 3a. The caudal border of S-I corresponds to the start of a cutaneous representation of the forepaw that appears to be part of S-III (see the text). An electrolytic lesion $(L)$ was made at the end of an electrode penetration. Area 4 (motor cortex) is indicated rostrally on the left. Scale equals $1 \mathrm{~mm}$.

representation corresponds to the traditional S-I of Adrian (1941) and Woolsey and co-workers (Woolsey and Fairman, 1946; Woolsey, 1958). (2) S-I in cats includes areas $3 \mathrm{~b}, 1$, and much of 2 , but not area $3 \mathrm{a}$ of Hassler and Muhs-Clement (1964). Therefore, the significance of fields $3 \mathrm{~b}, 1$, and 2 as described in cats is not the same as that for monkeys, where each field is coextensive with a separate representation of the body. To avoid confusion due to the inconsistent use of the terms $3 \mathrm{~b}, 1$, and 2 , we feel that they should not be used for architectonic distinctions within S-I of cats and other mammals. (3) S-I is responsive to cutaneous stimuli throughout. These conclusions are discussed further below.

What is $S-I$ ? The answer to the question "What is SI?" is not as simple as it appeared before the discovery of several separate body representations in cortex considered to be S-I in monkeys. However, from the first mapping studies of S-I in the cat (Marshall et al., 1941; Adrian, 1941, 1943) it appears that the intention was to describe a single somatotopic representation of the tactile sense. In extent and overall organization, the present summary map closely corresponds with that illustrated by Adrian (1941) as the first receiving area as defined with light tactile stimuli delivered with a camel's-hair brush and recorded with penetrating electrodes. The summaries later illustrated by Woolsey and Fairman (1946) and Woolsey (1958) were somewhat larger in extent than the present summary, but the use of surface recordings could account for much of the difference in size. For both Adrian (1941) and Woolsey and Fairman (1946), finding a region where parts of the body were represented a second time signified the existence of a second somatosensory area. Thus, our definition of S-I as a single systematic representation of the body surface is consistent with the historical concept of S-I in the cat.

Our recordings of deep receptor inputs in the region of area 3a (Hassler and Muhs-Clement, 1964) were considered to be outside of S-I, both because the responses were not from cutaneous stimuli and because body parts already represented in S-I were represented again in area $3 \mathrm{a}$. The inclusion of area 3a in S-I as part of a single cutaneous representation by McKenna et al. (1981) conflicts with the considerable evidence that the overwhelming majority of area 3 a neurons are driven by inputs from deep receptors (Anderson et al., 1966; Oscarsson and Rosén, 1963; 1966; Oscarsson et al., 1966; Landgren and Silfvenius, 1969; Zarzecki et al., 1978) and that the change from cutaneous to deep receptor driving occurs sharply at the border of "area 3b" with area 3a (Rasmusson et al., 1979; Dykes et al., 1980b). In addition, area 3a 
appears to contain a complete or nearly complete and separate representation of the body (Dykes et al., 1980b), and area 3 a receives input from a thalamic region that is distinct from the ventroposterior relay to S-I (Mallart, 1968; Rosén, 1969; Dykes et al., 1980a).

A number of somatosensory representations have now been described in cortex lateral and caudal to S-I in cats, including "S-II proper" and "S-II medial" (Burton et al., 1982), S-III (Tasker, 1960; Darian-Smith et al., 1966; Tanji et al., 1978; Garraghty et al., 1983), and S-IV (Burton et al., 1982; Clemo and Stein, 1982). In the present experiments, recordings along the caudal and lateral border of S-I were judged to be outside of S-I if the receptive fields were located on parts of the body surface already represented in S-I. At least part of the S-III region receives input from a part of the thalamus that is distinct from the ventroposterior relay to S-I (Tanji et al., 1978), and the ventroposterior inferior nucleus projects to the S-II region (Herron and Dykes, 1982), perhaps to "S-II medial."

The present summary map of S-I in the cat depicts an organization that is similar to the arrangement of body parts in S-I of prosimian primates (Krishnamurti et al., 1976; Sur et al., 1980a) and, with some modifications, in area 3b of monkeys (Merzenich et al., 1978; Kaas et al., 1979, Nelson et al., 1980; Sur et al., 1982; Felleman et al., 1983). Because of similarities in somatotopic organization, as well as connections, architecture, and neuron response properties, we have argued that the area $3 \mathrm{~b}$ representation of monkeys is the homologue of S-I in other mammals (Merzenich et al., 1978; Kaas et al., 1981; Kaas, 1983).

The relation of the present map to previous maps of $S$ $I$ in cats. Although aspects of the functional organization of the S-I region of cats have been extensively studied, the number of studies attempting to determine the total somatotopic pattern have been limited. The landmark report of Marshall et al. (1941) emphasized findings on monkeys and only briefly described the topography of somatosensory cortex in cats. Further limited observations on cats were presented by Haynes and Woolsey (1944), and later Woolsey and Fairman (1946) summarized the organization of somatosensory cortex with an illustration outlining S-I on the brain surface. Face, arm, and leg regions were indicated in the locations similar to those shown in the present map. The main differences appear to be that they included cortex somewhat more rostral and more caudal than the present map and located the representation for the postaxial leg on the medial wall of the cerebral hemisphere. Subsequently, Woolsey (1958) summarized unpublished data on the cat by C. N. Woolsey, Hayes, Cranston, and Luethy with a diagram of a distorted "homuncular" view of a cat superimposed on the cortex to indicate the organization of S-I. Other details of S-I organization were provided by Adrian (1941, 1943). The hindpaw, trunk, arm, forearm, wrist, and paw were shown in a mediolateral sequence across cortex in locations corresponding to those seen in the present experiment. The upper head, orbit, nose, mystacial vibrissae, and upper lip were shown in a sequence closely matching the representations shown in Figures 1, 2 , and 10 .
The first mapping study of the cat that illustrated extensive amounts of data unfortunately lacked a summary diagram (Rubel, 1971). Nevertheless, the illustrations of electrode penetration sites with the corresponding receptive fields and the description of results allow a detailed comparison with our findings. In general, the results of Rubel (1971) agree quite well with our conclusions. In particular, he illustrated the representation of the dorsal trunk in cortex rostral to the ventral trunk (Rubel, 1971, Fig. 2; present report, Fig. 3). In further agreement with the present results, Rubel (1971) found the tail on the medial wall, the digits of the hindlimb rostral to cortex devoted to the leg and trunk, the dorsoradial forelimb caudal to the forepaw, and the dorsal head caudolaterally. A recent limited exploration of part of S-I (Dykes et al., 1980b) emphasized the mediolateral sequence of representation in "area $3 \mathrm{~b}$ " of S-I, and the mediolateral sequence illustrated (foot, leg, pelvis, abdomen, thorax, shoulder, arm, forearm, wrist, digits) is one that could be constructed from the rostral part of our summary map, with the exception that we did not find the abdomen rostrally in S-I.

The final relevant mapping study of the S-I region of cats is that of McKenna et al. (1981). 'T'he authors' conclusion that "the data suggest that the total anterior parietal field (areas 3a, 3b, 1, and 2) of the cat is one continuous ... representation of the total low-threshold mechanoreceptor sheet" corresponds closely to the present conclusion that S-I includes areas $3 b, 1$, and much of 2 . However, we disagree with the inclusion of area $3 \mathrm{a}$ and the inclusion of a second caudal representation of the forepaw in the "single" cutaneous map. Within the region we consider to be S-I, there are further points of agreement and disagreement. The present report, Rubel (1971), Manzoni et al. (1980), and McKenna et al. (1981) all find the dorsal trunk representation to be rostral and the ventral trunk representation to be caudal in S-I. Arguments have been presented elsewhere that this is the basic orientation of the trunk representation in S-I (Sur et al., 1978; Kaas, 1983), and there is now broad agreement that the cat conforms to this plan. A minor point of disagreement concerns the orderly arrays of rostrocaudal bands of representation for the digits of the hindpaw and forepaw as portrayed by McKenna et al. (1981). If the portions of the bands extending into area $3 a$ are excluded, then the discrepancy with the present summary of representation of the hindpaw is not great, and the order of representation of digits 2 to 5 is in agreement. However, the digits of the forepaw are more accurately described from our results in the cat by a somewhat circular sequence, as they are in raccoons (Welker and Seidenstein, 1959). In addition, our results indicate several partial discontinuities within the representations of the forepaw and hindpaw.

The architectonic features of $S-I$ in the cat. Various investigators have divided the S-I region in cats by architectonic criteria in various ways. Campbell (1905) outlined a "sensory" region that roughly corresponds to the present S-I, and both Adrian (1941) and Marshall et al. (1941) noted the correspondence of the early physiological maps with this field. Brodmann (1909) and Gurewitsch and Chatschaturian (1928) included much or 
part of S-I in "motor" cortex. This error was discussed by Sanides and Hoffmann (1969), who ascribed it to the lack of fine granularization in somatosensory "koniocortex" of cats as compared to primates, and the presence of large layer $\mathrm{V}$ pyramidal cells in koniocortex of cats, especially in the part representing the hindlimb. Judgments of the architectonic extent of "motor" cortex could also have been influenced by early electrical stimulation results that include the S-I region in the motor field (e.g., Mann, 1896).

Clearly the architectonic study that has had the most impact on modern investigations of somatosensory cortex in cats is that of Hassler and Muhs-Clement (1964). These investigators illustrated three strip-like fields in the S-I region, and areas $3 \mathrm{~b}$ and 1 and most of area 2 of Hassler and Muhs-Clement (1964) appear to be within the present definition of S-I. The architectonic differences in these three fields, as described by Hassler and Muhs-Clement (1964), appear to be slight, largely depending on less distinct lamination, more compact layers, and less noticeable radial alignment of cells in area $3 \mathrm{~b}$. In viewing the photomicrographs in their paper (e.g., Figs. 11, 12, and 21), we were impressed with the uniformity of these three fields. In contrast, the illustrated borders of these fields with areas $5 \mathbf{a}$ and $3 \mathrm{a}$ were more distinct. From our material, and that illustrated by Hassler and Muhs-Clement (1964), we feel that borders between fields " $3 \mathrm{~b}, 1$, and 2 " would be difficult to define with precision and consistency. Although most studies of somatosensory cortex in cats have "used the criteria" of Hassler and Muhs-Clement (1964) to delimit their fields, often with no indication of how reliably architectonic boundaries could be distinguished, a number of investigators have commented on the difficulty of subdividing S-I into architectonic fields (e.g., McKenna et al., 1981).

Studies on other mammals with relatively smooth cortex and often more distinct architecture (rat, Welker, 1971; squirrel, Sur et al., 1978; tree shrew, Sur et al., 1980b; galago, Sur et al., 1980a) have convinced us that a single architectonic field, most appropriately termed somatic koniocortex (see Sanides and Hoffman, 1969), is coextensive with S-I. Our observations on the cytoarchitecture of the S-I region in cat are consistent with this conclusion, but a clear demonstration of a single architectonic field that is fully coextensive with S-I was confounded by the curved shape of S-I, the presence of the coronal and ansate sulci, which distort the architecture, and the less distinct appearance of somatic koniocortex in the cat. However, matching architectonic and physiological boundaries were convincingly demonstrated along limited portions of S-I where sections were cut perpendicular to boundaries (Fig. 11).

It is worth stressing that C. Welker (1971) clearly demonstrated the coextensiveness of S-I and somatic koniocortex in rats in both coronal brain sections and sections parallel to the surface of flattened brain preparations of previously mapped animals, even though other investigators have divided the S-I region of rats and mice into "areas 3, 1, and 2" (Krieg, 1946; Caviness, 1975). It is now obvious that the distinctions made in rodents and cats do not have the same significance as higher primates, and the use of the same terms in such different ways should be abandoned. Although S-I is not architectonically homogeneous, it is perhaps less confusing to consider the differences as variations within koniocortex or area $3 \mathrm{~b}$ rather than to use terms that signify separate body representations in monkeys.

Our conclusion that S-I in cats is a single field is not obviously contradicted by known physiology or anatomy. The proposed architectonic fields of S-I in cats $(3 \mathrm{~b}, 1$, and 2) do not appear to have distinctly different patterns of connections, as they do in monkeys (see Kaas, 1983, for review), and sharp changes in physiological properties have not been observed at the proposed boundaries. Dykes et al. (1980b), for example, were "unable to find any physiological difference" at the transition from area $3 \mathrm{~b}$ to area 1 in the cat, although they found an "abrupt" transition in properties at the $3 \mathrm{a} / 3 \mathrm{~b}$ border. Unlike the thalamic projection pattern for monkeys-where single locations in the ventroposterior nucleus project to separate locations in areas $3 \mathrm{~b}$ and 1 , and a more dorsal nucleus projects to area 2 (Lin et al., 1979; Nelson and Kaas, 1981)-small regions of the ventroposterior nucleus were found to project "across several cytoarchitectural regions of S-I" in cats (Hand and Morrison, 1970; see Kosar and Hand, 1981).

$S-I$ as a representation of cutaneous receptors. In the present experiments, neurons in electrode penetrations throughout S-I responded to cutaneous stimuli. In the typical experiment, all electrode penetrations within large portions of S-I encountered neurons responsive to cutaneous stimuli. Only neurons at border regions required more intense or different stimuli. Occasionally, penetrations within S-I failed to encounter neurons well driven by low threshold cutaneous stimuli, but there was never clear evidence that neurons in these penetrations were responsive to deep receptors, and one could assume that cortex was sometimes damaged or otherwise responding abnormally. We conclude that all parts of S-I are driven by cutaneous receptors and that no parts are driven exclusively from deep receptors. The conclusion is consistent with the early identification of S-I by Adrian (1941) and Marshall et al. (1941) as a cutaneous representation. Adrian (1941), for example, noted that "discharges due to touch can be obtained from every part of the receiving area." In contrast, the prevailing concept of S-I in cats, stemming from the report of Mountcastle (1957), is that the representation consists of a mosaic of intermingled modality-pure "columns" of neurons activated by either deep or cutaneous receptors. Because of this conflict in conclusions, it is useful to clarify what we mean by a cutaneous representation and to re-examine the evidence for input from deep receptors to S-I.

Our recordings were largely multiunit. Therefore, our finding that recording sites throughout S-I were responsive to cutaneous stimuli does not mean that inputs from deep receptors to S-I do not exist or even that single neurons in S-I are not exclusively activated via deep receptors. Such inputs could have been masked by a predominance of activity induced by cutaneous receptors, although such masking seems unlikely in view of the 
recent comparison of Dykes and Gabor (1981) of single and multiunit activity in the S-I region of cats. These investigators reported that single units almost always had the modality characteristics of the background activity. In addition we must allow for the possibility of convergent inputs from deep receptors that are suppressed by anesthesia. There does not seem to be any evidence that deep inputs are differentially affected by anesthesia. Yet, if such a pathway were more indirect, perhaps from other cortical areas rather than a thalamic relay, it might be more susceptible to disruption. Such an input would not be in columns, however, since we did not detect unresponsive columns in the present experiments. Although the possibilities of scattered inputs from deep receptors activating single neurons or deep receptor inputs convergent on cutaneously activated neurons are not eliminated by our observations, our observations are not consistent with the hypothesis that the representation includes exclusively "deep receptor" columns extending from surface to white matter and of up to $500 \mu$ in width.

The principal evidence for "deep receptor" columns in S-I of cats comes from Mountcastle (1957), who found that $26 \%$ of electrode penetrations perpendicular to the surface of cortex were modality pure and related to deep receptors only. In angled penetrations, long sequences of recording from "cells of first one and then another modality subgroup" suggested a pattern of intermingled narrow vertical columns of cells each activated by "a single mode of peripheral stimulation." In addition, several subsequent investigators have reported either the existence of submodality-pure vertical sequences of neurons related to deep receptors or the existence of inputs from deep receptors in the S-I region of cats (see Dykes, 1978 for review). More recently, Zarzecki and Wiggin (1982) have demonstrated the subthreshold excitation of neurons in S-I after electrical stimulation of forelimb nerves innervating deep structures. However, such findings do not necessarily indicate the existence of deep receptor columns or deep activating inputs to S-I, since several other explanations seem possible.

One possibility is that many of the modality-pure recordings from sequences of neurons activated by deep receptors have been from cortex rostral or caudal to S-I, as defined in this report. Mountcastle (1957) noted that the probability of encountering inputs from deep receptors increased when the recordings were rostral near the postcruciate dimple. Cortical architecture was not studied, and it seems probable that some of these penetrations were in area $3 \mathbf{a}$. A similar possibility is suggested by the results reported by McKenna et al. (1981) on the submodality distribution according to architectonic fields in S-I of cats. In "anterior area 1," that is, in cortex that must have been well centered in S-I and well away from any border, $96 \%$ of the neurons were reported as driven from the skin. In contrast, in "anterior area $3 b$," where the possibility of misidentification of the $3 a / 3 b$ border and recording from area $3 \mathrm{a}$ exists, $70 \%$ of the neurons were classified as related to deep receptors. Likewise, in the study of S-I neurons of Levitt and Levitt (1968), "zone A," which included area $3 \mathrm{a}$, had the highest per- centage of neurons activated by deep receptors. The issue of the nature of sensory input into areas $3 a$ and $3 b$ of cats has been discussed recently by Dykes et al. (1980b), who provided evidence that area $3 \mathrm{~b}$ is completely cutaneous, and that "deep responses in $3 \mathbf{b}$... are generated by difficulties in identifying the boundary precisely." An increase in input related to deep receptors has also been reported in caudal S-I (e.g., McKenna et al., 1981). It seems likely that at least some of these recordings have been from neurons outside of S-I. As a clear example, Iwamara and Tanaka (1978) noted deep receptor input to the second representation of the forepaw in the ansatc region, which they preferred to include in S-I, although they noted that this cortex had been classified by DarianSmith et al. (1966) as S-III.

Another possibility is that, to some extent, neurons in $\mathrm{S}$-I related to cutaneous receptors have been misclassified as related to deep receptors. Usually the classification of a neuron as noncutaneous is not confirmed by the dissection of tissue (however, see Mountcastle et al., 1952), and it is possible to activate cutaneous receptors by procedures that are typically used to activate deep receptors. Damaged or otherwise impaired neurons, or neurons in superficial cortical layers which are more difficult to activate (Dykes et al., 1980b), also may be incorrectly related to deep receptors. In addition, narrow zones of neurons with higher stimulus thresholds within S-I may have been misclassified as deep receptor columns. In rats (Welker, 1971) and squirrels (Sur et al., 1978), there are narrow zones coresponding to discontinuities in the representation, such as those between the representations of the forepaw and face, where neurons are difficult to drive. More recently, Dykes and Gabor (1981) have described narrow "transition zones" in S-I of cats where responses became weaker, thresholds became higher, and the receptive field locus shifted.

Our conclusion that S-I in cats is cutaneous throughout is supported by observations (Morse et al., 1965; Dykes et al., 1980b; Dykes and Gabor, 1981) that at least large regions of S-I appear to be activated only by cutaneous stimuli. Given the present summary map of S-I in the cat, it is clear that any large completely cutaneous region of cortex would include the representation of a number of body parts, and, therefore, these body parts at least would have no representation that is exclusively devoted to deep receptors in S-I. It is important to stress that, although it is possible to question the existence of direct activating pathways from deep receptors to S-I in cats, it is difficult to dismiss all evidence for such inputs. However, a clear demonstration of deep receptor inputs would not necessarily negate our contentions that S-I is cutaneously activated throughout or that large exclusively deep receptor cortical columns are not present.

If $\mathrm{S}$-I in the cat is activated by cutaneous stimuli throughout, it is logical to assume that the thalamic input to S-I is driven by cutaneous stimuli. All parts of S-I in cats appear to receive projections from the ventroposterior nucleus (Jones and Powell, 1969; Hand and Morrison, 1970; Saporta and Kruger, 1979; Kosar and Hand, 1981). From the first mapping studies, the ventroposterior nucleus of the cat was described as cutaneous, 
although the existence of other inputs was postulated (Mountcastle and Henneman, 1949). Like S-I, the ventroposterior nucleus has been thought of as a nucleus with mixed somatosensory inputs (see Welker, 1973 for revicw), and there is evidence from denuded limb experiments of inputs from deep receptors (Mountcastle et al., 1952). However, in squirrel monkeys, the ventroposterior "proper" or "core" relays cutaneous information to cortex, whereas information from deep receptors is relayed via adjoining regions of the thalamus (Dykes et al., 1981). In cats, Gordon and Manson (1967) reported that the "great majority" of cells in the "main core" of the ventroposterior nucleus were cutaneously activated. Likewise, Golovchinsky et al. (1981) found that the "vast majority" of neurons in the "core" of the ventroposterior nucleus were responsive to mechanical stimulation of the skin. Yin and Williams (1976) found the thalamic joint neurons in the cat to be located within a shell-like border region of the ventroposterior nucleus. Harris (1978) attributed his failure to find joint units in the ventroposterior nucleus to the possibility that the relay region is outside, although perhaps adjacent to this nucleus. Inputs from muscle spindle receptors apparently are also absent from the ventroposterior nucleus and are confined to a separate region of the thalamus, ventroposterior oralis, which projects to area $3 \mathrm{a}$ of cortex (Oscarsson and Rosén, 1966; Dykes et al., 1980a). The inference from these observations is that the ventral thalamus of cats consists of separate submodality-specific regions, with a cutaneous "core" nucleus projecting to S-I.

As a final comment on the responsiveness of S-I in cats, our evidence does not exclude the possibility of columns of cutaneous submodalities. The strip-like segregation of slowly adapting (SA) and rapidly adapting (RA) inputs as reported for S-I of cats (Rasmusson et al., 1979; Dykes et al., 1980b; Dykes and Gabor, 1981;

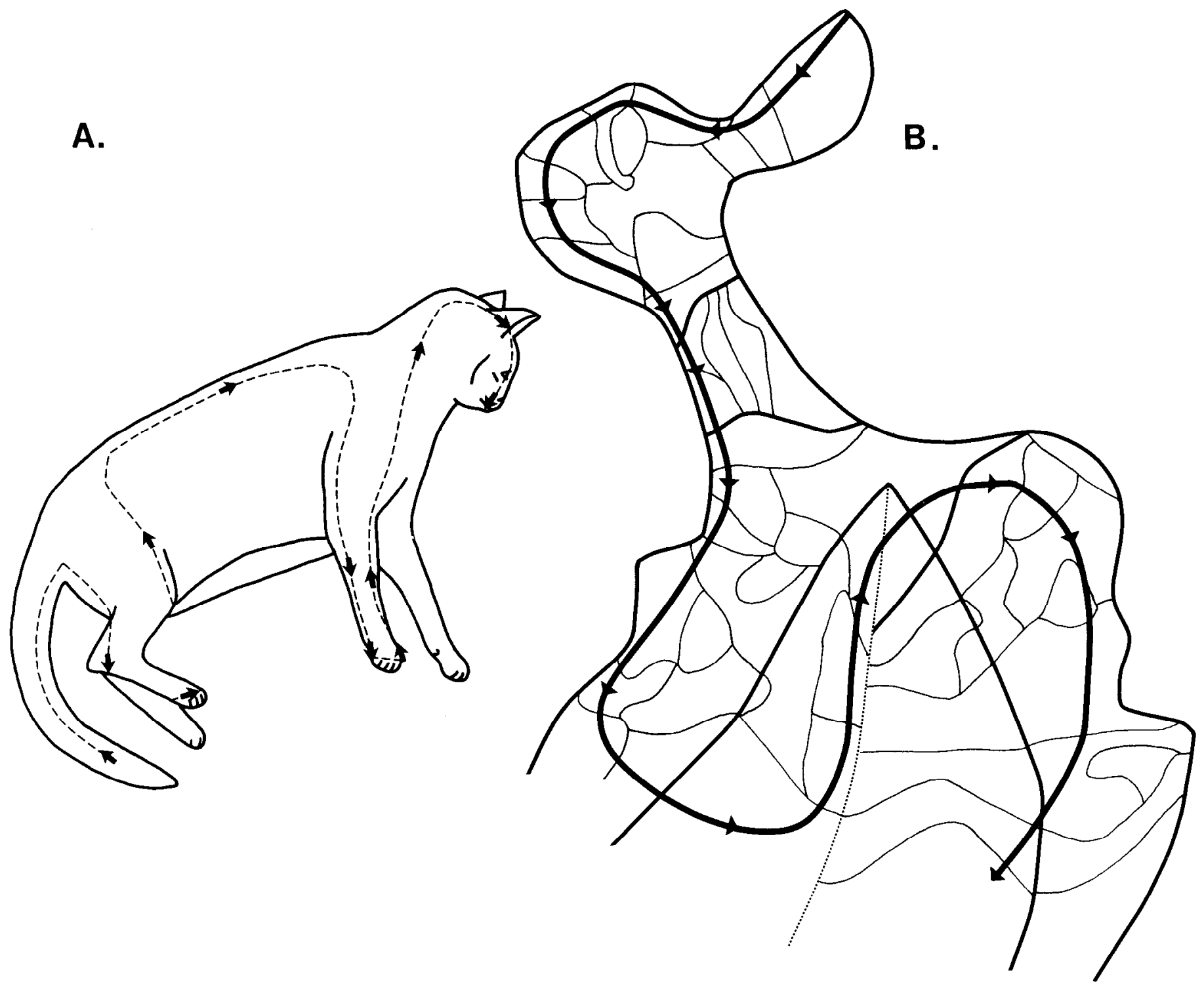

Figure 12. Orientation of the body surface representation in cat S-I. The relation between the body surfaces ( $A$ ) and their representation in S-I cortex $(B)$. The dashed line indicates a continuous path from tail to chin on the body surface and the corresponding path in S-I. See Figure 2 for a detailed description of the composite cortical map. 
Sretavan and Dykes, 1983) and area 3b of monkeys (Sur et al., 1981) is not contradicted by our results. However, a logical requirement for such bands, given the proposed organization of S-I, is that the SA and RA bands are narrow enough so that any body part in the representation encompasses neurons in both types of bands.

Continuity and discontinuity within $S-I$ of the cat. As for the S-I and the S-I "proper" (area $3 \mathrm{~b}$ ) representations in other species, there were obvious disruptions in the somatotopic order in S-I of the cat. Thus, parts of the face were represented in cortex immediately adjacent to the hand, the representations of the hairy and glabrous nose were separated, the hairy surfaces of paw digits disrupted the glabrous representations of the digits, and parts of the leg and arm representations were split into separate cortical locations. Because of such discontinuities, which probably result in part from the requirements of representing a three-dimensional surface on a twodimensional cortex and in part from the different magnification factors for different body surfaces, we have referred to S-I as a composite of somatotopic regions (Merzenich et al., 1978). The disruptions in S-I, however, are not complete, so that the somatotopic regions have at least limited adjacencies that are somatotopic. Thus, there are lines of continuity throughout the map. An example of one such line is shown in Figure 12. The roughly medial to lateral line across S-I corresponds to a continuous tail to chin sequence on the body surface. The particular sequence illustrated also indicates the somatotopic separation of anterior and posterior leg and arm and the rostral representation of the dorsal trunk.

\section{References}

Adrian, E. D. (1940) Double representation of the feet in the sensory cortex of the cat. J. Physiol. (Lond.) 98: 16P.

Adrian, E. D. (1941) Afferent discharges to the cerebral cortex from peripheral sense organs. J. Physiol. (Lond.) 100: 159. 191.

Adrian, E. D. (1943) Afferent areas in the brain of ungulates. Brain 66: 7-103.

Anderson, S. A., S. Landgren, and D. Wolsk (1966) The thalamic relay and the cortical projection of group I muscle afferents from the forelimb of the cat. J. Physiol (Lond.) 183: 576-591.

Berman, A. L. (1961) Overlap of somatic and auditory cortical response fields in anterior ectosylvian gyrus of cat. J. Neurophysiol. 24: 595-607.

Brodmann, K. (1909) Vergleichende Lokalisationslehre der Grosshirnrinde, Barth, Leipzig.

Burton, H., G. Mitchell, and D. Brent (1982) Second somatic sensory area in the cerebral cortex of cats: Somatotopic organization and cytoarchitecture. J. Comp. Neurol. 210: 109-135.

Campbell, A. W. (1905) Histological Studies of the Localisation of Cerebral Function, p. 360, Cambridge University Press, Cambridge.

Caviness, V. S., Jr., (1975) Architectonic map of neocortex of the normal mouse. J. Comp. Neurol. 164: 247-264.

Clemo, H. R., and B. E. Stein (1982) Somatosensory cortex: A "new" somatotopic representation. Brain Res. 235: 162-168.

Darian-Smith, I., J. Isbister, H. Mok, and T. Yokota (1966) Somatic sensory cortical projection areas excited by tactile stimulation of the cat: A triple representation. J. Physiol (Lond.) 182: 671-689.
Dykes, R. W. (1978) The anatomy and physiology of the somatic sensory cortical regions. Prog. Neurobiol. 10: 33-88.

Dykes, R. W., and A. Gabor (1981) Magnification functions and receptive field sequences for submodality-specific bands in S-I cortex of cats. J. Comp. Neurol. 202: 597-620.

Dykes, R. W., Dudar, J. D., Tanji, D. G., and Publicover, N. G. (1977) Somatotopic projections of the mystacial vibrissae upon the cerebral cortex of cats. J. Neurophysiol. 10: $997-$ 1014.

Dykes, R. W., C.-S. Lin, and N. Rehman (1980a) Thalamocortical projection nuclei for modality-specific regions of somatosensory cortex: Demonstration of different projections for areas $3 \mathbf{a}$ and $3 \mathbf{b}$ of the cat. Physiologist 23: 73 .

Dykes, R. W., D. D. Rasmusson, and P. B. Hoeltzell (1980b) Organization of primary somatosensory cortex in the cat. J. Neurophysiol. 43: 1527-1546.

Dykes, R. W., M. Sur, M. M. Merzenich, J. H. Kaas, and R. J. Nelson (1981) Regional segregation of neurons responding to quickly adapting, slowly adapting, deep and Pacinian receptors within thalamic ventroposterior lateral and ventroposterior inferior nuclei in the squirrel monkey (Saimiri sciureus). Neuroscience 6: 1687-1692.

Felleman, D. J., J. T. Wall, C. G. Cusick, and J. H. Kaas (1981) Evidence for a single cutaneous representation within the SI region of the cat. Anat. Rec. 199: $82 \mathrm{~A}$.

Felleman, D. J., R. J. Nelson, M. Sur, and J. H. Kaas (1983) Representations of the body surface in areas $3 \mathrm{~b}$ and 1 of postcentral parietal cortex of cebus monkeys. Brain Res., in press.

Garraghty, P. E., T. P. Pons, and J. H. Kaas (1983) A representation of the body surface in the $\mathrm{S}$-III region of somatosensory cortex in cats. Anat. Rec. 205: 60A.

Golovchinsky, V., L. Kruger, S. A. Saporta, B. E. Stein, and D. W. Young (1981) Properties of velocity-mechanosensitive neurons in the cat ventrobasal thalamic nucleus with special reference to the concept of convergence. Brain Res. 209: 355374.

Gordon, G., and J. R. Manson (1967) Cutaneous receptive fields of single nerve cells in the thalamus of the cat. Nature 215: 597-599.

Gurewitsch, M., and A. Chatschaturian (1928) Zur Cytoarchitektonik der Grosshirnrinde des Felides. Z. Anat. 87: 100138.

Haight, J. R. (1972) The general organization of somatotopic projections to SII cerebral neocortex in the cat. Brain Res. 11: 483-502.

Hand, P. J., and A. R. Morrison (1970) Thalamocortical projections from the ventrobasal complex to somatic sensory areas I and II. Exp. Neurol. 26: 291-308.

Harris, F. A. (1978) Regional variations of somatosensory input convergence in nucleus VPL of cat thalamus. Exp. Neurol. 58: $171-189$.

Hassler, R., and K. Muhs-Clement (1964) Architektonischer Aufbau des sensorimotorischen und parietalen Cortex der Katze. J. Hirnforsch. 6: 377-420.

Haynes, G. J., and C. N. Woolsey (1944) The pattern of organization within the primary tactile area of cerebral cortex of the cat. Fed. Proc. 3: 18.

Herron, P., and R. W. Dykes (1981) Connections of the ventroposterior inferior nucleus of the thalamus in cats. Soc. Neurosci. Abstr. 7: 396.

Iwamura, Y., and M. Tanaka (1978) Functional organization of receptive fields in the cat somatosensory cortex. II. Second representation of the forepaw in the ansate region. Brain Res. 151: 61-72.

Jones, E. G., and R. Porter (1980) What is area 3a? Brain Res. Rev. 2: 1-43.

Jones, E. G., and T. P. S. Powell (1969) The cortical projection 
of the ventroposterior nucleus of the thalamus in the cat. Brain Res. 13: 298-318.

Kaas, J. H. (1983) What, if anything, is S I?: The organization of the "first somatosensory area" of cortex. Physiol. Rev. 63: $206-230$.

Kaas, J. H., R. J. Nelson, M. Sur, C. -S. Lin, and M. M. Merzenich (1979) Multiple representations of the body within the primary somatosensory cortex of primates. Science 204: 521-523.

Kaas, J. H., R. J. Nelson, M. Sur, and M. M. Merzenich (1981) Organization of somatosensory cortex in primates. In The Organization of the Cerebral Cortex: Proceedings of a Neurosciences Research Colloquium, Woods Hole, Mass., U. S. A., F. O. Schmitt, F. G. Worden, G. Adelman, S. G. Dennis, eds., pp. 237-262, MIT Press, Cambridge, MA.

Kawamura, K. (1971) Variations of the cerebral sulci in the cat. Acta Anat. 80: 204-221.

Kosar, F., and P. .J. Hand (1981) First somatosensory cortical columns and associated neuronal clusters of nucleus ventralis posterolateralis of the cat: An anatomical demonstration. J. Comp. Neurol. 198: 515-539.

Krieg, W. J. S. (1946) Connections of the cerebral cortex. I. The albino rat. A topography of the cortical areas. J. Comp. Neurol. 84: 221-275.

Krishnamurti, A., F. Sanides, and W. I. Welker (1976) Microelectrode mapping of modality-specific somatic sensory cerebral neocortex in slow loris. Brain Behav. Evol. 13: 267-283.

Landgren, S., and Silfvenius, H. (1969) Projection to cerebral cortex of group I muscle afferents from cat's hind limb. J. Physiol (Lond.) 200: 353-372.

Levitt, J., and M. Levitt (1968) Sensory hind-linb representation in SmI cortex of the cat. A unit analysis. Exp. Neurol. 22: $259-275$.

Lin, C. -S., M. M. Merzenich, M. Sur, and J. H. Kaas (1979) Connections of areas $3 \mathrm{~b}$ and 1 of the parietal somatosensory strip with the ventroposterior nucleus in the owl monkey (Aotus trivirgatus). J. Comp. Neurol. 185: 355-372.

Mallart, A. (1968) Thalamic projection of muscle nerve afferents in the cat. J. Physiol. (Lond.) 194: 337-353.

Mann, G. (1896) Homoplasty of the brain of rodents, insecti vores, and carnivores. J. Anat. Physiol. 30: 1-35.

Manzoni, T., D. Barbaresi, E. Bellardinelli, and R. Caminiti (1980) Callosal projections from the two body midlines. Exp. Brain Res. 39: 1-9.

Marshall, W. H., C. N. Woolsey, and P. Bard (1937) Cortical representation of tactile sensibility as indicated by cortical potentials. Science 85: $388-390$.

Marshall, W. H., C. N. Woolsey, and P. Bard (1941) Observations on cortical somatic sensory mechanisms of cat and monkey. J. Neurophysiol. 4: 1-24.

McKenna, T. M., B. L. Whitsel, D. A. Dreyer, and C. B. Metz (1981) Organization of cat anterior parietal cortex: Relations among cytoarchitecture, single neuron functional properties and interhemispheric connectivity. J. Neurophysiol. 45:667697.

McKenna, T. M., B. L. Whitsel, and D. A. Dreyer (1982) Anterior parietal cortical topographic organization in macaque monkey: A re-evaluation. J. Neurophysiol. 48: 289311.

Merzenich, M. M., J. H. Kaas, M. Sur, and C. -S. Lin (1978) Double representation of the body surface within cytoarchitectonic areas $3 \mathrm{~b}$ and 1 in "SI" in the owl monkey (Aotus trivirgatus). J. Comp. Neurol. 181: 41-74.

Morse, R. W., Adkins, R. J., and Towe, A. L. (1965) Population and modality characteristics of neurons in the coronal region of somatosensory area I of the cat. Exp. Neurol. 11:419-440.

Mountcastle, V. B. (1957) Modality and topographic properties of single neurons of cat's somatic sensory cortex. J. Neurophysiol. 20: 408-434.

Mountcastle, V. B., and E. Henneman (1949) Pattern of tactile representation in thalamus of cat. J. Neurophysiol. 12: 85100.

Mountcastle, V. B., M. R. Covian, and C. R. Harrison (1952) The central representation of some forms of deep sensibility. Res. Publ. Assoc. Nerv. Ment. Dis. 30: 339370.

Nelson, R. J., and J. H. Kaas (1981) Connections of the ventroposterior nucleus of the thalamus with the body surface representations in cortical areas $3 \mathrm{~b}$ and 1 of the cynomolgus macaque (Macaca fascicularis). J. Comp. Neurol. 199. 29-64.

Nelson, R. J., M. Sur, and J. H. Kaas (1979) The organization of the second somatosensory area (SmII) of the grey squirrel. J. Comp. Neurol. 184: 473-490.

Nelson, R. J., M. Sur, D. J. Felleman, and J. H. Kaas (1980) The representations of the body surface in postcentral somatosensory cortex of Macaca fascicularis. J. Comp. Neurol. 192: $611-644$

Oscarsson, O., and I. Rosén (1963) Projection to cerebral cortex of large muscle spindle afferents in forelimb nerves of the cat. J. Physiol. (Lond.) 169: 924-945.

Oscarsson, O., and I. Rosén (1966) Short latency projections to the cat's cerebral cortex from skin and muscle afferents in the contralateral forelimb. J. Physiol. (Lond.) 182: 164-184.

Oscarsson, O., I. Rosén, and I. Sulg (1966) Organization of neurones in the cat cerebral cortex that are influenced from group I muscle afferents. J. Physiol. (Lond.) 183: 189-210.

Otsuka, R., and R. Hassler (1962) Über Aufbau und Gliederung der corticalen Sehsphäre bei der Katze. Arch. Psychiatr. Neurol. 203: 213-234.

Rasmusson, D. D., R. W. Dykes, and P. B. Hoeltzell (1979) Segregation of modality and submodality information in SI cortex of cat. Brain Res. 166: 409-412.

Rosén, I. (1969) Excitation of group I activated thalamocortical relay neurons in the cat. J. Physiol. (Lond.) 205: 14-35.

Rubel, E. W. (1971) A comparison of somatotopic organization in sensory neocortex of newborn kittens and adult cats. J. Comp. Neurol. 143: 447-480.

Sanides, F., and J. Iloffmann (1969) Cyto- and myeloarchitecture of the visual cortex of the cat and of the surrounding integration cortices. J. Hirnforsch. 11: 79-104.

Saporta, S., and L. Kruger (1979) The organization of projections to selected points in somatosensory cortex from the cat ventrobasal complex. Brain Res. 178: 275-295.

Sretavan, D., and R. W. Dykes (1983) The organization of two cutaneous submodalities in the forearm region of area $3 \mathrm{~b}$ of cat somatosensory cortex. J. Comp. Neurol. 213: 381-398.

Sur, M., R. J. Nelson, and J. H. Kaas (1978) The representation of the body surface in somatosensory area I of the grey squirrel. J. Comp. Neurol. 179: 425-449.

Sur, M., R. J. Nelson, and J. H. Kaas (1980a) Representation of the body surface in somatic koniocortex in the prosimian Galago. J. Comp. Neurol. 189: 381-402.

Sur, M., R. E. Weller, and J. H. Kaas (1980b) The representation of the body surface in the first somatosensory area of the tree shrew, Tupaia glis. J. Comp. Neurol. 194: 71-95.

Sur, M., J. 'I: Wall, and J. H. Kaas (1981) Modular segregation of functional cell classes with the postcentral somatosensory cortex of monkeys. Science 212: 1059-1061.

Sur, M., R. J. Nelson, and J. H. Kaas (1982) Representation of the body surface in cortical areas $3 b$ and 1 of squirrel monkeys: Comparisons with other primates. J. Comp. Neurol. 211: $177-192$.

Tanji, D. G., S. P. Wise, R. W. Dykes, and F. G. Jones (1978) Cytoarchitecture and thalamic connectivity of the third so- 
matosensory area of the cat cerebral cortex. J. Neurophysiol. 41: $268-284$.

Tasker, R. R. (1960) A third somatic tactile sensory area. Physiologist, 3: 162.

Waters, R. S., O. Favorov, and H. Asanuma (1982) Physiological properties and pattern of projection of cortico-cortical connections from the anterior bank of the ansate sulcus to the motor cortex, area $4 \gamma$ in the cat. Exp. Brain Res. 46: 403412.

Welker, C. (1971) Microelectrode delineation of fine grain somatotopic organization of $\mathrm{SmI}$ cerebral neocortex in albino rat. Brain Res. 26: 259-275.

Welker, W. I. (1973) Principles of organization of the ventrobasal complex in mammals. Brain Behav. Evol. 7: 253-336.

Welker, W. I., and S. Seidenstein (1959) Somatic sensory representation in the cerebral cortex of the raccoon (Procyon lotor). J. Comp. Neurol. 111: 469-502.

Winkler, C., and A. Potter (1914) An Anatomical Guide to Experimental Researchers on the Cat's Brain, W. Versluys,
Amsterdam.

Woolsey, C. N. (1958) Organization of somatic sensory and motor areas of the cerebral cortex. In Biological and Biochemical Bases of Behavior, H. F. Harlow and C. N. Woolsey, eds., pp. 63-81, The University of Wisconsin Press, Madison.

Woolsey, C. N., and D. Fairman (1946) Contralateral, ipsilateral and bilateral representation of cutaneous receptors in somatic areas I and II of the cerebral cortex of pig, sheep, and other mammals. Surgery 19: 684-702.

Yin, T. C. T., and W. J. Williams (1976) Dynamic response and transfer characteristics of joint neurons in somatosensory thalamus of the cat. J. Neurophysiol. 39: 582-600.

Zarzecki, P., and D. M. Wiggin (1982) Convergence of sensory inputs upon projection neurons of somatosensory cortex. Exp. Brain Res. 48: 28-42.

Zarzecki, P., T. Shiroda, and H. Asanuma (1978) Projection from area $3 \mathrm{a}$ to the motor cortex by neurons activated from group I muscle afferents. Exp. Brain Res. 33: 269-282. 